\title{
Modelling of primary aerosols in the chemical transport model MOCAGE: development and evaluation of aerosol physical parameterizations
}

\author{
B. Sič, L. El Amraoui, V. Marécal, B. Josse, J. Arteta, J. Guth, M. Joly, and P. D. Hamer \\ CNRM-GAME, Météo-France and CNRS, UMR3589, Toulouse, France
}

Correspondence to: B. Sič (bojan.sic@meteo.fr)

Received: 24 February 2014 - Published in Geosci. Model Dev. Discuss.: 29 April 2014

Revised: 19 January 2015 - Accepted: 28 January 2015 - Published: 23 February 2015

\begin{abstract}
This paper deals with recent improvements to the global chemical transport model of Météo-France MOCAGE (Modèle de Chimie Atmosphérique à Grande Echelle) that consists of updates to different aerosol parameterizations. MOCAGE only contains primary aerosol species: desert dust, sea salt, black carbon, organic carbon, and also volcanic ash in the case of large volcanic eruptions. We introduced important changes to the aerosol parameterization concerning emissions, wet deposition and sedimentation. For the emissions, size distribution and wind calculations are modified for desert dust aerosols, and a surface sea temperature dependant source function is introduced for sea salt aerosols. Wet deposition is modified toward a more physically realistic representation by introducing re-evaporation of falling rain and snowfall scavenging and by changing the in-cloud scavenging scheme along with calculations of precipitation cloud cover and rain properties. The sedimentation scheme update includes changes regarding the stability and viscosity calculations. Independent data from satellites (MODIS, SEVIRI), the ground (AERONET, EMEP), and a model inter-comparison project (AeroCom) are compared with MOCAGE simulations and show that the introduced changes brought a significant improvement on aerosol representation, properties and global distribution. Emitted quantities of desert dust and sea salt, as well their lifetimes, moved closer towards values of AeroCom estimates and the multimodel average. When comparing the model simulations with MODIS aerosol optical depth (AOD) observations over the oceans, the updated model configuration shows a decrease in the modified normalized mean bias (MNMB; from 0.42 to 0.10 ) and a better correlation (from 0.06 to 0.32 ) in terms of the geographical distribution and the temporal variabil-
\end{abstract}

ity. The updates corrected a strong positive MNMB in the sea salt representation at high latitudes (from 0.65 to 0.16 ), and a negative MNMB in the desert dust representation in the African dust outflow region (from -1.01 to -0.22 ). The updates in sedimentation produced a modest difference; the MNMB with MODIS data from 0.10 in the updated configuration went to 0.11 in the updated configuration only without the sedimentation updates. Yet, the updates in the emissions and the wet deposition made a stronger impact on the results; the MNMB was 0.27 and 0.21 in updated configurations only without emission, and only without wet deposition updates, respectively. Also, the lifetime, the extent, and the strength of the episodic aerosol events are better reproduced in the updated configuration. The wet deposition processes and the differences between the various configurations that were tested greatly influence the representation of the episodic events. However, wet deposition is not a continuous process; it has a local and episodic signature and its representation depends strongly on the precipitation regime in the model.

\section{Introduction}

Atmospheric aerosols play a major role in a number of atmospheric processes and have an important global climate impact (IPCC, 2007). Increased effort has been made in the domain of aerosol modelling as knowledge of their importance has increased (Textor et al., 2006). The goal of the modelling has been to qualitatively and quantitatively represent aerosols in the correct way in order to better understand how aerosols affect atmospheric chemistry, air quality, 
climate, aviation, visibility, radiative budget and clouds. For this task, it is necessary to develop reliable parameterizations that describe how aerosols are emitted, transported and transformed, and, in the end, removed from the atmosphere. Owing to this drive to improve model representation of aerosols, and due to the complexity of aerosol processes, a large diversity of parameterizations now exists. This variety produces a wide range of model results (Mahowald et al., 2003; Tegen, 2003; Textor et al., 2006). Therefore, the choice, development and validation of used parameterizations are crucial for the performance of the models (Lee et al., 2011).

Sources of aerosols are more difficult to define than those of gases (IPCC, 2007). In models, aerosol sources are characterized either by interactive emission parameterizations that depend on soil properties and/or wind intensity - which are, in the case of primary aerosols, generally used for desert dust and sea salt particles - or by existing emission inventories, mainly used for other primary aerosol types. Secondary aerosols are not directly emitted and they originate from gasphase precursors or from reactions between dissolved or adsorbed gases and primary aerosols. The AEROCOM model inter-comparison run with and without harmonized emissions (Textor et al., 2007) showed that, although the uncertainties in emissions can be large, after the emission harmonization the inter-model diversity decreased slightly but remained large. The standard deviation of the total aerosol burden decreased from $18 \mathrm{Tg}$, for non-harmonized emissions, to $16 \mathrm{Tg}$, for harmonized emissions. Therefore, in addition to emissions, other model components, like the parameterizations of physical processes, contribute significantly to the model uncertainties.

Removal processes balance against the emission and production processes, and determine the lifetime of aerosols in the atmosphere. They are especially important for species that do not interact chemically (i.e. primary aerosols) because they represent their only available sinks. Mechanisms which remove aerosols are divided in two groups: "wet" deposition (scavenging) processes which take place in the interaction of aerosols with precipitation, and "dry" processes which include gravitational sedimentation (or gravitational settling) and dry deposition by interaction with the surface. The comparison of the models and their performance compared to dust measurements after long-range transport by Prospero et al. (2010) showed that the ratios of different deposition mechanisms varied greatly among the models and against the observed ratios. For example, the ratios of wet deposition to dry deposition ranged from about $1: 1$ to $30: 1$ in the models, in contrast from about $3: 1$ to $4: 1$ at the measurement stations. This and findings from the other studies demonstrate that aerosol deposition is complex and challenging to implement in an accurate way (Rasch et al., 2000; Sportisse, 2007; Prospero et al., 2010).

Wet deposition is the most efficient aerosol sink (Pruppacher et al., 1997), but it is regionally limited. Its uncertainty is augmented by the uncertainties in precipitation and aerosol properties, and wet deposition is identified as a key source of uncertainty in aerosol models (Vignati et al., 2010; IPCC, 2013). Rasch et al. (2000) showed in an intercomparison that model simulations differ most strongly in the upper troposphere for species undergoing wet scavenging processes. In all wet deposition processes, particles are indirectly transferred to the surface with the aid of precipitation. Inside clouds, in-cloud scavenging (rain-out) occurs when precipitation forms. Aerosols can act as condensation nuclei for the formation of water droplets and small cloud particles. When water vapour interacts with their surface, it can start to condense and allow the cloud droplets to grow. Additional aerosol particles can then be attracted and absorbed into them. When a droplet starts to precipitate, below-cloud scavenging (wash-out) takes place. While falling, a droplet can collide with aerosol particles and collect them from the air. Although less efficient than in-cloud scavenging, below-cloud scavenging is particularly important for coarse and very small particles (Andronache, 2003). Wet deposition is commonly parameterized by the scavenging coefficient $\Lambda\left(\mathrm{s}^{-1}\right)$ where $\frac{\mathrm{d} c}{\mathrm{~d} t}=-\Lambda c, c$ is the aerosol concentration. Many methods have been proposed in the literature to estimate the scavenging coefficient (e.g. Sportisse, 2007): more theoretical approaches, semi-empirical parameterizations with detailed modelling of various component processes that are responsible for aerosol deposition, or fully empirical approaches with a large number of different proposed formulations.

Aerosols undergo the influence of gravitational forces and tend to fall because their mass is not negligible. Near the surface, the dry deposition process acts together with gravitational sedimentation and it is especially efficient for coarse and very fine particles (Seinfeld and Pandis, 1998). Particles interact with the surface and objects in a thin layer of air next to the surface: they experience drag, change velocities and fall down. The velocity of dry deposition depends on properties of the surface, aerosols particles, and meteorological parameters (Seinfeld and Pandis, 1998).

Uncertainties in the models do not only come from the different formulations of deposition parameterization. Uncertainties in meteorological fields can also have a significant effect on model performance. Winds control the transport of species and can influence the interactive emission parameterizations. The humidity determines cloud coverage, rain localization and intensity - which are crucial for wet deposition processes - and hygroscopic particle growth, which is important for the particle settling and visibility.

In the present study we examine all of the previously mentioned processes in the chemical transport model (CTM) MOCAGE (Modèle de Chimie Atmosphérique à Grande Echelle). The CTM MOCAGE was developed at MétéoFrance and contributes to a wide range of scientific studies. Its applications cover both regional and global scales and extend to air-quality forecasts, climate-chemistry interactions (Teyssèdre et al., 2007; Lamarque et al., 2013), desert aerosol 
Table 1. Bin ranges of individual primary aerosol species present in MOCAGE.

\begin{tabular}{lllllll}
\hline & bin 1 & bin 2 & bin 3 & bin 4 & bin 5 & bin 6 \\
\hline Desert dust $(\mu \mathrm{m})$ & $0.1-1$ & $1-2.5$ & $2.5-5$ & $5-10$ & $10-30$ & $30-100$ \\
Sea salt $(\mu \mathrm{m})$ & $0.003-0.13$ & $0.13-0.3$ & $0.3-1$ & $1-2.5$ & $2.5-10$ & $10-20$ \\
Black carbon $(\mu \mathrm{m})$ & $0.0001-0.001$ & $0.001-0.003$ & $0.003-0.2$ & $0.2-1$ & $1-2.5$ & $2.5-10$ \\
Organic carbon $(\mu \mathrm{m})$ & $0.0005-0.003$ & $0.003-0.1$ & $0.1-0.3$ & $0.3-1$ & $1-2.5$ & $2.5-10$ \\
\hline
\end{tabular}

studies (Martet et al., 2009), long-range transport pollution studies (Bousserez et al., 2007), "chemical weather" (Dufour et al., 2005), data assimilation of chemical species (e.g. El Amraoui et al., 2010), troposphere-stratosphere transport (Ricaud et al., 2009; Barré et al., 2012), etc. For its applications relating to aerosols, the CTM MOCAGE is implicated in a number of projects: MACC (www.gmes-atmosphere.eu), PREV'AIR (www.prevair.org), IMPACT2C (www.hzg.de/ mw/impact2c/), and VAAC (Volcanic Ash Advisory Centre) predictions. The model outputs that are used in these projects are aerosol optical depth (AOD) and particulate matter concentrations $\left(\mathrm{PM}_{2.5}\right.$ and $\mathrm{PM}_{10}$ - particulate matter up to $2.5 / 10 \mu \mathrm{m}$ in size).

Many aerosol processes are highly inter-connected; uncertainties and different formulations of processes lead to a large dispersion of model results as shown in comparative studies (Rasch et al., 2000; Textor et al., 2007; Prospero et al., 2010). This reveals the importance and complexity of aerosol physical parameterizations. In this paper, we present the recent developments on primary aerosol emissions and physical parameterizations in the CTM MOCAGE. Our main objective is to improve the aerosol representation in the model. To achieve this objective, we will, firstly, reexamine and modify primary aerosol emissions and parameterizations (wet scavenging and sedimentation) in MOCAGE; secondly, study sensitivities to different formulations of the mentioned processes in order to show how different treatments influence the aerosol representation in the model and to which extent their uncertainties affect the model performance; and thirdly, evaluate the new parameterizations for emissions, wet deposition, and sedimentation in MOCAGE by comparing the model outputs with different satellite and ground observations. We perform this evaluation for two physical quantities important for model applications: AOD and PM concentrations. The analysis and evaluation are based on the model output at the global scale for the year 2007.

The article is organized as follows. In Sect. 2 we present the general description of the model MOCAGE. The aerosol parameterizations in the model and their improvements are presented in detail in Sect. 3. Section 4 describes all observational data sets used for comparison with the model. In Sect. 5 we define the model experiments and explain the method used to assess model performance. Results and discussions are presented in Sects. 6 and 7 where we compare MOCAGE results with different independent observations and evaluate a new set of parameterizations in MOCAGE to estimate their impact on aerosol burden, lifetime, concentration, deposition and optical depth. Section 8 concludes this study.

\section{General description of the model}

MOCAGE is a global chemistry and transport model (CTM) developed at Météo-France. It is used as an operational air quality model simulating gases (Josse et al., 2004; Dufour et al., 2005) and primary aerosols (Martet et al., 2009). It transports atmospheric species by a semi-lagrangian advection scheme (Williamson and Rasch, 1989). Turbulent diffusion is implemented following Louis (1979), and convection following Bechtold et al. (2001). The dynamics within the CTM are forced by ARPEGE meteorological analysis fields (pressure, winds, temperature, specific humidity). ARPEGE is the operational global numerical weather prediction model of Météo-France. The precipitation field and liquid water content are calculated in MOCAGE in the same way as in ARPEGE. MOCAGE has 47 vertical hybrid sigma-pressure levels from the surface up to about $5 \mathrm{hPa}$. The vertical resolution is not uniform; levels are packed more densely near the surface, with a resolution of $40 \mathrm{~m}$ in the planetary boundary layer, about $400 \mathrm{~m}$ in the free troposphere and about 700$800 \mathrm{~m}$ in the upper troposphere and lower stratosphere. In the global configuration, simulations have a horizontal resolution of $2^{\circ}$ latitude $\times 2^{\circ}$ longitude.

Aerosols in MOCAGE are considered as an external mix of four primary aerosol species: desert dust, sea salt, black carbon (BC), organic carbon (OC) and volcanic ash. Volcanic ash aerosols are included only in the case of large volcanic eruptions and they are not considered in this study. The particle size distribution is divided across size bins, which are treated as passive tracers: aerosols are emitted, transported and removed from the atmosphere, and no transformations or chemical reactions between the different aerosol species or with gases are allowed. Each of the species has six size bins where we consider only the averaged mass and diameter of particles. The size ranges of bins for all considered aerosol species are shown in Table 1. The number of bins per species is limited to six in order to balance the operational cost and effectiveness. Two of the bins have their limits at 2.5 and $10 \mu \mathrm{m}$ for practical air quality purposes in order to easily integrate the sum of $\mathrm{PM}_{2.5}$ and $\mathrm{PM}_{10}$ particles. The 
other bin size ranges are distributed in a such manner as to have an optimal aerosol representation considering the initial size distribution and evolution of each aerosol species in the model.

AOD in the model is calculated at $550 \mathrm{~nm}$ using Mie theory with refractive indices taken from the Global Aerosol Data Set (GADS; Köpke et al., 1997) and extinction efficiencies derived with Wiscombe's Mie scattering code for homogeneous spherical particles (Wiscombe, 1980). The water uptake of the sea salt, as a hydrophilic species, is considered in the AOD calculations by changes of the physical dimensions and the size parameter of the particles and also by its influence on the particle refractive index. To calculate the modified refractive index, we interpolate the GADS data for the ambient relative humidity.

\section{Aerosol parameterizations in the model}

In this section we describe the aerosol parameterizations in MOCAGE, as well as developments and updates that we have made to the parameterizations as part of this study. From now on, the present MOCAGE configuration will be referred to as SIM1, and the configuration with updated parameterizations as SIM2. For the complete description of the SIM1 and SIM2 configurations, the reader is referred to Sect. 5 .

\subsection{Dry deposition}

Dry deposition of aerosol particles in the model is based on the Slinn and Slinn (1980) and Slinn (1982b) studies that describe the deposition process as a transport to the surface in terms of resistances in series aided by particle sedimentation. The complete scheme is described in detail in Nho-Kim et al. (2004). Briefly, the process of particulate dry deposition is composed of transport through the atmospheric surface layer governed by turbulent diffusion (aerodynamical resistance), the transport in the quasi-laminar layer influenced by diffusion, interception and impaction (quasi-laminar layer resistance), and adherence to the surface which is considered totally efficient. Each of these mechanisms contributes to the deposition velocity. The characteristics of the surface are defined as in the ARPEGE model which includes physical parameters of soils (roughness length, vegetation type) necessary for particle-surface interaction. The dry deposition velocity is defined as

$V_{\mathrm{dd}}=\frac{1}{R_{\mathrm{a}}+R_{\mathrm{b}}}+V_{\mathrm{p}}$,

where $R_{\mathrm{a}}$ is the aerodynamical resistance $\left(\mathrm{s} \mathrm{m}^{-1}\right), R_{\mathrm{b}}$ is the quasi-laminar resistance $\left(\mathrm{s} \mathrm{m}^{-1}\right)$, and $V_{\mathrm{p}}$ is the settling velocity $\left(\mathrm{m} \mathrm{s}^{-1}\right)$. The aerosol dry deposition scheme is not a subject to the changes in this study.

\subsection{Sedimentation}

Gravitational settling of aerosol particles is implemented as described in Seinfeld and Pandis (1998). The settling velocity is based on Stokes law and is a function of particle diameter, particle density, and air viscosity:

$V_{\mathrm{p}}=\frac{D_{\mathrm{p}}^{2} \rho_{\mathrm{p}} g C_{\mathrm{c}}}{18 \mu_{\mathrm{a}}}$,

where $D_{\mathrm{p}}$ is the ambient aerosol diameter $(\mathrm{m}), \rho_{\mathrm{p}}$ is the aerosol particle density $\left(\mathrm{kg} \mathrm{m}^{-3}\right), g$ is the gravitational constant $\left(\mathrm{m} \mathrm{s}^{-2}\right), \mu_{\mathrm{a}}$ is the dynamical viscosity of air (Pas), and $C_{\mathrm{c}}$ is the slip correction factor which accounts for noncontinuum effects when the particle diameter and the air mean free path are of the same order of magnitude. $C_{\mathrm{c}}$ is defined as (Seinfeld and Pandis, 1998)

$C_{\mathrm{c}}=1+\frac{2 \lambda}{D_{\mathrm{p}}}\left[1.257+0.4 \exp \left(-\frac{1.1 D_{\mathrm{p}}}{2 \lambda}\right)\right]$,

where $\lambda$ is the mean free path of an air particle (m).

In the model configuration SIM1, we calculate the dynamical air viscosity using an assumed constant value of the kinematic viscosity. In the updated sedimentation calculations, in SIM2, we calculate it by Sutherland's law, an empirical relation connecting dynamical viscosity and temperature (White, 1991):

$\mu_{\mathrm{a}}=\mu_{0} \frac{T_{0}+S}{T+S}\left(\frac{T}{T_{0}}\right)^{3 / 2}$,

where $\mu_{0}$ is the reference dynamical viscosity of air at the reference temperature $T_{0}$ with values of $\mu_{0}=1.716 \times$ $10^{-5} \mathrm{Pas}$ and $T_{0}=273 \mathrm{~K}$, and $S=111 \mathrm{~K}$ is Sutherland's effective temperature (White, 1991).

Finally, in SIM2, to ensure the stability and the mass conservation of our explicit sedimentation scheme, sedimentation velocity is not allowed to exceed one gridbox height per model time step.

\subsection{Wet deposition}

The fraction of aerosols removed at each time step by interaction with precipitation (by both in-cloud and below-cloud scavenging) is calculated as

$F=f_{\text {prec }}\left(1-e^{-\Lambda \Delta t}\right)$,

where $F$ is the fraction of removed aerosols, $f_{\text {prec }}$ is the fraction of precipitating cloud cover (the percentage of a cloud coverage in a gridbox where precipitation forms or falls); $\Lambda$ is the scavenging coefficient $\left(\mathrm{s}^{-1}\right)$ which describes a rate of loss of particles due to scavenging; $\Delta t$ is the model time step for scavenging (s). The scavenging coefficient, $\Lambda$, consists of the in-cloud scavenging coefficient, $\Lambda_{\text {ro }}$, and the belowcloud scavenging coefficient due to rainfall, $\Lambda_{\mathrm{wo}}$, and due to snowfall, $\Lambda_{\text {so }}$. To calculate them, we use the respective incloud and below-cloud parameterized schemes described in the following. 


\section{Cloud cover of precipitation cloud cover}

In SIM1, we use a simple approach by considering that if precipitation forms in the gridbox it happens in all available cloud cover in the gridbox. To better represent the precipitating cloud cover in MOCAGE, we updated the model by adapting in SIM2 a scheme from Giorgi and Chameides (1986). To estimate the portion of the sky covered by precipitating clouds, this scheme considers typical conditions in stratiform and convective clouds during the formation of precipitation and compares them with the modelled gridbox mean precipitation formation rates. Precipitation formation rates are calculated by the diagnostic scheme that uses the cloudiness scheme from Xu and Randall (1996) and the precipitation scheme from Kessler (1969). For stratiform clouds, the fraction of precipitation forming clouds is (we also take all values of quoted parameters from Giorgi and Chameides (1986) if not stated differently)

$f_{\text {strat }}=\frac{Q}{\left(L_{\mathrm{st}} \cdot R_{\mathrm{st}}+Q\right)}$,

where $Q$ is the gridbox mean rate of precipitation formation including both liquid and solid precipitation $\left(\mathrm{kg} \mathrm{m}^{-3} \mathrm{~s}^{-1}\right)$. $L_{\text {st }}$ is the typical in-cloud liquid water content in precipitation forming stratiform clouds: $L_{\mathrm{st}}=1.5 \times 10^{-3} \mathrm{~kg} \mathrm{~m}^{-3}$, from Brost et al. (1991). It differs from the value originally proposed by Giorgi and Chameides (1986), $L_{\mathrm{st}}=0.5 \times$ $10^{-3} \mathrm{~kg} \mathrm{~m}^{-3}$, taken from Pruppacher and Klett (1978). The value from Giorgi and Chameides (1986) was corrected by Brost et al. (1991) and later adopted by Jacob et al. (2000) and Liu et al. (2001). $R_{\text {st }}$ is the in-cloud rate constant of conversion of cloud water to precipitation for stratiform precipitation: $R_{\mathrm{st}}=1 \times 10^{-4} \mathrm{~s}^{-1}$.

For convective clouds, the fraction of precipitating cloud cover within a gridbox for any given time step is

$f_{\mathrm{conv}}=\frac{F_{0} Q \frac{\Delta t}{t_{\mathrm{c}}}}{Q \frac{\Delta t}{t_{\mathrm{c}}}+F_{0} R_{\mathrm{cv}} L_{\mathrm{cv}}}$,

where $F_{0}$ is the maximum cumulus cloud cover assumed in the radiation calculations backed by observations, $F_{0}=0.3$; $\Delta t$ is the model time step; $t_{\mathrm{c}}$ is the typical duration of precipitation from a cumulonimbus cloud, $t_{\mathrm{c}}=30 \mathrm{~min}$ (Liu et al., 2001); $R_{\mathrm{cv}}$ is the in-cloud rate constant of conversion of cloud water to precipitation in convective clouds, $R_{\mathrm{cv}}=$ $1.5 \times 10^{-3} \mathrm{~s}^{-1}$; and $L_{\mathrm{cv}}$ is the typical in-cloud liquid water content in cumulonimbus clouds, $L_{\mathrm{cv}}=2 \times 10^{-3} \mathrm{~kg} \mathrm{~m}^{-3}$.

\section{Implemented schemes}

To estimate the scavenging coefficient $\Lambda$ and its components, many parameterizations have been developed and Sportisse (2007) summarizes them adequately. In our model, the current parameterization for in-cloud scavenging, used in SIM1, is the Langner and Rodhe (1991) scheme and in this study it will be evaluated against the Giorgi and Chameides (1986) scheme, which is implemented in the SIM2 configuration. Additionally, in this study we modified and re-evaluated the model's current below-cloud scavenging scheme based on Slinn (1977).

\subsubsection{In-cloud scavenging}

The in-cloud scavenging coefficient according to Langner and Rodhe (1991) is directly proportional to the precipitation formation rate:

$\Lambda_{\text {ro }}=\frac{\epsilon Q}{L}$

where $L$ is the gridbox mean liquid water content in the rain-forming cloud $\left(\mathrm{kg} \mathrm{m}^{-3}\right)$, and $\epsilon$ is the scavenging efficiency of a species uptake during the formation of precipitation. The scavenging efficiencies are based on KasperGiebl et al. (2000) where a distinction is made between insoluble (aerosol carbon) and soluble aerosols (sulfates). The scavenging efficiency depends on the liquid water content (LWC). But, for the high $\operatorname{LWC}\left(>0.5 \times 10^{-3} \mathrm{~kg} \mathrm{~m}^{-3}\right)$, which is typical of the precipitating clouds, the scavenging efficiency is considered constant (Kasper-Giebl et al., 2000). The values derived by Kasper-Giebl et al. (2000) are, for the soluble species (only sea salt aerosols in our model), 0.83 and, for insoluble species, 0.6. This scheme is not size dependent.

The parameterization of Giorgi and Chameides (1986) depends on the type of precipitation by taking into account typical conditions in stratiform and convective clouds when precipitation forms. But, it does not depend on a particle size, nor a particle type. For stratiform precipitation the scavenging coefficient equals

$\Lambda_{\mathrm{ro}_{\mathrm{st}}}=R_{\mathrm{st}}+\frac{Q}{L_{\mathrm{st}}}$.

And for convective precipitation, the scavenging coefficient is

$\Lambda_{\mathrm{ro}_{\mathrm{cv}}}=R_{\mathrm{cv}}$.

\subsubsection{Rain below-cloud scavenging}

Below-cloud scavenging in the model acts in all gridboxes, and gridbox fractions, where precipitation falls. However, below-cloud scavenging cannot occur in the same gridboxes, or gridbox fractions, where precipitation forms. In order to calculate the fraction of a particular gridbox where belowscavenging acts we examine the overlying layers above that gridbox and find the layer with the maximum precipitation fraction. We then subtract from this maximum fraction, the fraction where in-cloud scavenging acts in the gridbox we are examining. The rain below-cloud scavenging coefficient is defined as in Seinfeld and Pandis (1998):

$\Lambda_{\mathrm{wo}}=\frac{3}{2} \frac{E_{\mathrm{r}} P}{D_{\mathrm{d}}}$, 
where $E_{\mathrm{r}}$ is the collection efficiency of a raindrop to collect a particle during its fall, $P$ is the precipitation rate in precipitating area $\left(\mathrm{kg} \mathrm{m}^{-2} \mathrm{~s}^{-1}\right)$, and $D_{\mathrm{d}}$ is the raindrop diameter (m). To permit both, rain-out and wash-out, to take place in the same gridbox at the same time, we revised the condition for when and where wash-out occurs, and we now assume that it happens in all regions exactly below the rain-out area.

We calculate the collection efficiency using Slinn's belowcloud scavenging scheme (Slinn, 1977), described also in Seinfeld and Pandis (1998) and widely used in models (Wang et al., 2010). Slinn's scheme considers collisions between a falling raindrop and an aerosol particle, and accounts for Brownian diffusion, interception and impaction. The collision efficiency is a function of the sizes of raindrops and aerosols, and is expressed as (Slinn, 1977)

$$
\begin{aligned}
& E_{\mathrm{r}}=\frac{4}{\operatorname{Re} S c}\left(1+0.4 \operatorname{Re}^{1 / 2} S c^{1 / 3}+0.16 R e^{1 / 2} S c^{1 / 2}\right) \\
& +4 \phi\left[\omega^{-1}+\left(1+2 R e^{1 / 2}\right) \phi\right] \\
& +\left(\frac{S t k-S t k^{*}}{S t k-S t k^{*}+\frac{2}{3}}\right)^{3 / 2} \cdot\left(\frac{\rho_{\mathrm{d}}}{\rho_{\mathrm{p}}}\right)^{1 / 2},
\end{aligned}
$$

where $R e=\frac{D_{\mathrm{d}} V_{\mathrm{d}} \rho_{\mathrm{a}}}{2 \mu_{\mathrm{a}}}$ is the Reynolds number of the raindrops based on their radius, $V_{\mathrm{d}}=\frac{D_{\mathrm{d}}^{2} \rho_{\mathrm{d}} g C_{\mathrm{c}}}{18 \mu_{\mathrm{a}}}$ is the terminal raindrop velocity as used in SIM1 (expression based on Stokes law) $\left(\mathrm{m} \mathrm{s}^{-1}\right), \rho_{\mathrm{a}}$ and $\rho_{\mathrm{d}}$ are the density of air and water $\left(\mathrm{kg} \mathrm{m}^{-3}\right)$, $S c=\frac{\mu_{\mathrm{a}}}{\rho_{\mathrm{a}} D}$ is the Schmidt number of the collected aerosol particles, $D=\frac{k T_{\mathrm{a}} C_{\mathrm{c}}}{3 \pi \mu_{\mathrm{a}} D_{\mathrm{p}}}$ is the aerosol diffusivity $\left(\mathrm{m}^{2} \mathrm{~s}\right), k$ is the Boltzmann constant $\left(\mathrm{JK}^{-1}\right), T_{\mathrm{a}}$ is the air temperature $(\mathrm{K})$, $S t k=\frac{2 \tau\left(V_{\mathrm{d}}-V_{\mathrm{p}}\right)}{D_{\mathrm{d}}}$ is the Stokes number of the collected particles, $\tau=V_{\mathrm{p}} / g$ is the characteristic relaxation time (s), Stk $k^{*}=$ $\frac{1.2+\frac{1}{12} \ln (1+R e)}{1+\ln (1+R e)}$ is the critical Stokes number, $\phi=D_{\mathrm{p}} / D_{\mathrm{d}}$ is the ratio of diameters of the aerosol particle and the rain droplet, and $\omega$ is the viscosity ratio of air and water. Considering terminal raindrop velocity, the expression defined above, used in SIM1, covers only the Stokes flow regime. But, the majority of raindrops falls with velocities out of the Stokes flow regime where inertial forces must be regarded, that is true for $D_{\mathrm{d}}>2 \times 10^{-5} \mathrm{~m}$ (Seinfeld and Pandis, 1998). The expressions of the raindrop terminal velocity which cover the whole raindrop size range are based on experimental data. From Brown and Lawler (2003), in SIM2 we use

$$
V_{\mathrm{t}}=\frac{V_{\mathrm{d}}}{1+0.17 \sqrt{R e}}
$$

where $V_{\mathrm{d}}$ is the Stokes flow velocity defined earlier, and $R e$ is the corresponding Reynolds number at the Stokes velocity.

In SIM1, the raindrop diameter is presumed to be fixed with the value of $1 \mathrm{~mm}$. To examine effects of this assumption we consider raindrops to be also distributed in size. In SIM2, we use the exponential raindrop distribution from Marshall and Palmer (1948).
The first term in the collision efficiency equation (Eq. 12) describes Brownian diffusion and is the most important for the smallest particles $\left(D_{\mathrm{p}}<0.2 \mu \mathrm{m}\right)$, while the second and the third terms describe interception and inertial impaction which dominate for bigger particles $\left(D_{\mathrm{p}}>1 \mu \mathrm{m}\right)$ (Seinfeld and Pandis, 1998).

\section{Phoretic and electric effects}

The scavenging calculated due to diffusion, interception and impaction showed possible underestimation of scavenged quantities when compared with field measurements (Davenport and Peters, 1978; Laakso et al., 2003). Some authors broaden scavenging by including more mechanisms - thermophoresis, diffusiophoresis, and electric effects (Davenport and Peters, 1978; Chate, 2005; Andronache et al., 2006). Thermophoresis makes particles move along a temperature gradient; diffusiophoresis makes particles move due to gas concentration gradients (e.g. motion toward the raindrop during condensation); and electric forces make charged particles interact with each other. We included these effects to Eq. (12) in the SIM2_BCPLUS configuration (Table 2) as (Davenport and Peters, 1978)

Thermophoresis $E_{\mathrm{th}}=\frac{4 \alpha\left(2+0.6 \operatorname{Re}^{\frac{1}{2}} \operatorname{Pr}^{\frac{1}{3}}\right)\left(T_{\mathrm{a}}-T_{\mathrm{s}}\right)}{V_{\mathrm{t}} D_{\mathrm{d}}}$,

Diffusiophoresis $E_{\mathrm{df}}=\frac{4 \beta\left(2+0.6 R e^{\frac{1}{2}} S c_{\mathrm{w}}^{\frac{1}{3}}\right)\left(\frac{P_{\mathrm{s}}^{0}}{T_{\mathrm{s}}}-\frac{P^{0} \mathrm{RH}}{T_{\mathrm{a}}}\right)}{V_{\mathrm{t}} D_{\mathrm{d}}}$,

Electrostatic charge $E_{\mathrm{ec}}=\frac{16 K C_{\mathrm{c}} a^{2} \gamma^{2} D_{\mathrm{p}}}{3 \pi \mu_{\mathrm{a}} V_{\mathrm{t}}}$,

where $\alpha=\frac{2 C_{\mathrm{c}}\left(k_{\mathrm{a}}+\frac{5 \lambda}{D_{\mathrm{p}} k_{\mathrm{p}}}\right) k_{\mathrm{a}}}{5 P\left(1+\frac{6 \lambda}{D_{\mathrm{p}}}\right)\left(2 k_{\mathrm{a}}+k_{\mathrm{p}}+\frac{10 \lambda}{D_{\mathrm{p}} k_{\mathrm{p}}}\right)}, k_{\mathrm{a}}$ and $k_{\mathrm{p}}$ are the thermal conductivity of air and aerosol particle $\left(\mathrm{J} \mathrm{m}^{-1} \mathrm{~s}^{-1} \mathrm{~K}^{-1}\right), P$ is the atmospheric pressure (Pa), $\operatorname{Pr}=\frac{c_{p} \mu_{\mathrm{a}}}{k_{\mathrm{a}}}$ is the Prandtl number for air, $c_{p}$ is the specific heat capacity of air $\left(\mathrm{m}^{2} \mathrm{~s}^{-2} \mathrm{~K}^{-1}\right)$, $T_{\mathrm{S}}$ is the temperature at the surface of the raindrop and it is taken to be $1 \mathrm{~K}$ less that the air temperature (Slinn and Hales, $1971), \beta=\frac{T_{\mathrm{a}} D_{\mathrm{w}}}{P}\left(\frac{M_{\mathrm{w}}}{M_{\mathrm{a}}}\right), D_{\mathrm{w}}=2.1 \times 10^{-5}\left(\frac{T_{\mathrm{a}}}{T_{0}}\right)^{1.94}\left(\frac{P}{P_{0}}\right)$ is the water vapour diffusivity (Pruppacher et al., 1997), $M_{\mathrm{w}}$ and $M_{\mathrm{a}}$ are the molecular weights of water and air, respectively, $S c_{\mathrm{w}}=\frac{\mu_{\mathrm{a}}}{\rho_{\mathrm{a}} D_{\mathrm{w}}}$ is the Schmidt number for water vapour in air, $P_{\mathrm{s}}^{0}$ and $P^{0}$ are the water vapour partial pressures (in $\mathrm{Pa}$ ) at temperatures $T_{\mathrm{s}}$ and $T_{\mathrm{a}}$, respectively, $\mathrm{RH}$ is the relative humidity, $K$ is the Coulomb constant, $a$ is a constant $a=$ $0.83 \times 10^{-6}$, and $\gamma$ is the parameter of cloud electricity and it is taken as an averaged value $\gamma=2$ (Pruppacher et al., 1997; Andronache, 2004). 
Table 2. Description of MOCAGE simulations used in this study.

\begin{tabular}{|c|c|c|}
\hline Simulation & \multicolumn{2}{|l|}{ Description } \\
\hline 1. SIM1 & $\begin{array}{l}\text { The reference simulation } \\
\text { in-cloud scavenging: } \\
\text { below-cloud scavenging: } \\
\text { emissions } \\
\text { - sea salt: } \\
\text { - desert dust: } \\
\text { - carbonaceous aerosols: }\end{array}$ & $\begin{array}{l}\text { the current MOCAGE configuration } \\
\text { the Langner and Rodhe (1991) scheme } \\
\text { the Slinn (1977) scheme with fixed raindrop size and } \\
\text { Stoke's regime terminal raindrop velocity } \\
\text { the Gong (2003) source function } \\
\text { the Marticorena et al. (1997) and Laurent et al. (2006) } \\
\text { schemes with the nearest-neighbour wind interpolation } \\
\text { AeroCom + GFED3 emissions }\end{array}$ \\
\hline 2. SIM2 & $\begin{array}{l}\text { emissions } \\
\text { - sea salt: } \\
\text { - desert dust: } \\
\text { - carbonaceous aerosols: } \\
\text { sedimentation: }\end{array}$ & $\begin{array}{l}\text { the updated model configuration } \\
\text { the Giorgi and Chameides (1986) scheme and precipitation } \\
\text { cloud cover } \\
\text { the Slinn (1977) rainfall scheme with the exponential rain- } \\
\text { drop size distribution, the parameterized terminal raindrop } \\
\text { velocity and the precipitation re-evaporation; the Slinn } \\
\text { (1977, 1982a) snowfall scheme } \\
\text { the Jaegle et al. (2011) source function } \\
\text { the Marticorena et al. (1997) and Laurent et al. (2006) } \\
\text { schemes with the bilinear wind interpolation and the Al- } \\
\text { faro et al. (1998) desert dust initial distribution } \\
\text { Lamarque et al. (2010) + GFED3 emissions } \\
\text { introduction of Sutherland's law + stability check }\end{array}$ \\
\hline 3. SIM2_WDEP & \multicolumn{2}{|c|}{ As SIM2, but wet deposition module as in SIM1 } \\
\hline 4. SIM2_SED & \multicolumn{2}{|c|}{ As SIM2, but sedimentation module as in SIM1 } \\
\hline 5. SIM2_EMI & \multicolumn{2}{|c|}{ As SIM2, but emissions as in SIM1 } \\
\hline 6. SIM2_BCPLUS & \multicolumn{2}{|c|}{$\begin{array}{l}\text { As SIM2 plus thermophoretic, diffusiophoretic and electric charge effects in the } \\
\text { below-cloud scavenging scheme }\end{array}$} \\
\hline
\end{tabular}

\subsubsection{Below-cloud scavenging due to snowfall}

We extended the scavenging module in SIM2 by adding snowfall scavenging. Often, precipitation in liquid state at the surface originates from solid state precipitation at higher altitudes. Tests in MOCAGE show that snowfall wash-out occurs in a larger number of gridboxes than rainfall washout. Compared to rainfall scavenging, there are fewer studies of the scavenging due to snowfall and there is a wider set of necessary snowfall parameters (due to different types and shapes of snow particles), which lead to larger uncertainties in the aerosol scavenging due to snowfall in the models. Also, snow scavenging efficiencies measured by different authors have a wide range of values: some are similar to those of rainfall, but some are 1 order of magnitude larger or lower (Sportisse, 2007).

Within MOCAGE, we introduce the Slinn (1977, 1982a) snowfall scavenging formula, which is one of the most commonly used snowfall parameterizations (Gong et al., 1997; Croft et al., 2009; Zhang et al., 2013). All snow crystals in this study are assumed to be formed by riming. The snow- fall below-cloud scavenging coefficient is given as (Slinn, 1982a):

$\Lambda_{\mathrm{so}}=\frac{\gamma E_{\mathrm{s}} P}{D_{\mathrm{m}}}$

where $E_{\mathrm{s}}$ is the collection efficiency of a snow crystal to collect a particle during its fall, $\gamma$ is the dimensionless fractional constant (in our case 0.5 ), and $D_{\mathrm{m}}$ is the characteristic volume-to-area length scale (for the rimed crystals $D_{\mathrm{m}}=2.7 \times 10^{-5} \mathrm{~m}$, Slinn, 1982a).

The Slinn (1977, 1982a) formulation is aerosol size, aerosol-type and snow-crystal-type dependent. The collection efficiency of the snow crystals is

$$
\begin{aligned}
E_{\mathrm{s}} & =\left(\frac{1}{S c}\right)^{\delta}+\left[1-\exp \left[-\left(1+\sqrt{R e_{l}}\right) \frac{D_{\mathrm{p}}^{2}}{l^{2}}\right]\right] \\
& +\left(\frac{S t k-S t k^{*}}{S t k-S t k^{*}+\frac{2}{3}}\right)^{3 / 2} \cdot\left(\frac{\rho_{\mathrm{s}}}{\rho_{\mathrm{p}}}\right)^{1 / 2},
\end{aligned}
$$

where the exponent $\delta$ depends on the snow-crystal type, $l$ is the characteristic length of collecting ice filaments, and 
$R e_{l}$ is the corresponding Reynolds number; $\rho_{\mathrm{s}}=100 \mathrm{~g} \mathrm{~m}^{-3}$ is the density of falling snow. For rimed snow crystals that we consider in the model: $l=100 \mu \mathrm{m}, \operatorname{Re}_{l}=10$ and $\delta=$ $\frac{2}{3}$ (Slinn, 1977). Since we consider only rimed crystals of a fixed size, terminal settling velocity is considered constant: $V_{\mathrm{s}}=0.9 \mathrm{~m} \mathrm{~s}^{-1}$ (Todd, 1964).

\subsubsection{Re-evaporation}

We introduced precipitation re-evaporation in the belowscavenging module in SIM2. If the fraction $f$ of precipitation evaporates at one level, then the corresponding $0.5 f$ fraction of scavenged aerosols will be released back to the atmosphere. The factor of 0.5 (Liu et al., 2001) is due to the fact that water molecules are more efficiently released than aerosols. If precipitation evaporates completely, then all scavenged aerosols are released. Sublimation of snowfall is not taken in account, and it is presumed that all solid precipitation would first melt and then evaporate.

\subsection{Emissions}

All considered species are emitted as particles, i.e. primary aerosols. For emissions of black carbon and organic carbon we use prepared emission inventories, while for desert dust and sea salt we use online parameterizations.

The anthropogenic carbonaceous aerosol emissions in the SIM1 configuration come from the monthly defined AeroCom emission inventory (Dentener et al., 2006). Dentener et al. (2006) is based on Bond et al. (2004), which used the reference year 1996. In the SIM2 configuration, the organic carbon and black carbon anthropogenic emissions come from the inventory of Lamarque et al. (2010). Lamarque et al. (2010) monthly defined emissions are based on Bond et al. (2007) and Junker and Liousse (2008), which are harmonized with the reference year 2000. Lamarque et al. (2010) updated these previous inventories using other studies regarding additional emission sources (coal burning, domestic biofuel, ship tracks). Biomass burning emissions for both organic carbon and black carbon come from the GFEDv3 project (van der Werf et al., 2010). In GFEDv3, the data from biogeochemical modelling and active fire satellite measurements (MODIS and GOES) are combined to a daily state-of-the-art biomass burning emission estimate (Mu et al., 2011). Biomass burning carbon emissions are injected more quickly to higher altitudes compared to other emissions, due to fire-induced convection. The maximal injection height depends on fire heat flux and environmental conditions, and varies significantly with latitude. In our model we have defined the maximal injection height in the tropical regions to be $1000 \mathrm{~m}$, in midlatitudes $4000 \mathrm{~m}$, and in the boreal regions $6000 \mathrm{~m}$. Our choice is consistent with Williams et al. (2009).

The black carbon and organic carbon initial sizedistribution is defined using a two-mode lognormal distribution with the number mode diameters of the two modes as $r_{1}=1.5 \times 10^{-8} \mathrm{~m}$ and $r_{2}=4 \times 10^{-8} \mathrm{~m}$, the geometric standard deviation $\sigma_{1}=\sigma_{2}=1.8$, and the mass distribution between modes frac $_{1}=0.4$ and frac $_{2}=0.6$ (Dentener et al., 2006).

\subsubsection{Sea salt source function}

Monahan et al. (1986) developed a formulation for the production of sea salt particles resulting from the bursting of wind-formed sea surface bubbles. Their semi-empirical formulation depends on the particle size and the intensity of surface winds. Gong (2003) addressed the overestimation of small particles $(D<0.2 \mu \mathrm{m})$ compared with observations and proposed an improved formulation. The rate of sea salt particle production (particles $\mathrm{m}^{-2} \mathrm{~s}^{-1} \mu \mathrm{m}^{-1}$ ) became (Gong, 2003)

$\frac{\mathrm{d} F}{\mathrm{~d} r}=1.373 u_{10}^{3.41} r^{-A}\left(1+0.057 r^{3.45}\right) \times 10^{1.607 e^{-B^{2}}}$,

where $r$ is the particle radius at relative humidity of $80 \%$, $u_{10}$ is the wind speed at $10 \mathrm{~m}$ above the surface $\left(\mathrm{m} \mathrm{s}^{-1}\right)$, and the parameters $A=4.7(1+30 r)^{-0.017 r^{-1.44}}$ and $B=$ $(0.433-\log r) / 0.433$. Jaeglé et al. (2011) compared modelled data with AOD and sea salt measurements from coastal stations, satellites and ocean cruises, and found that the Gong (2003) function at high wind speeds $\left(>6 \mathrm{~m} \mathrm{~s}^{-1}\right)$ overestimates sea salt concentrations over cold waters, and underestimates them over tropical waters. Their modified sea salt source function includes a sea surface water temperature dependence (Jaeglé et al., 2011):

$$
\begin{aligned}
\frac{\mathrm{d} F}{\mathrm{~d} r}= & \left(0.3+0.1 T-0.0076 T^{2}+0.00021 T^{3}\right) \\
& \cdot 1.373 u_{10}^{3.41} r^{-A}\left(1+0.057 r^{3.45}\right) \times 10^{1.607 e^{-B^{2}}},
\end{aligned}
$$

where $T$ is the sea surface temperature $\left(\mathrm{SST} ;{ }^{\circ} \mathrm{C}\right)$. The possible mechanisms of how sea surface temperature influences sea salt production are mentioned in Jaeglé et al. (2011): they are connected with kinetic viscosity of water and the gas exchange efficiency which leads to stronger whitecaps coverage in warmer waters (Lewis and Schwartz, 2004; Anguelova and Webster, 2006). In MOCAGE, the sea salt source function proposed by Gong (2003) is used in SIM1, and the Jaeglé et al. (2011) modification is implemented in SIM2 and evaluated in this study. Both of these formulas use particle size at relative humidity of $80 \%$, and to calculate a dry particle sea salt source function we use the Gerber (1985) hygroscopic growth formula:

$r=\left(\frac{C_{1} r_{\mathrm{d}}^{C_{2}}}{C_{3} r_{\mathrm{d}}^{C_{4}}-\log \mathrm{RH}}+r_{\mathrm{d}}^{3}\right)^{\frac{1}{3}}$,

where $r_{\mathrm{d}}$ is the dry particle radius $(\mathrm{cm})$; $\mathrm{RH}$ is the relative humidity in percentage; $r$ is the particle size at the RH relative humidity; and $C_{1}=0.7664, C_{2}=3.079, C_{3}=2.573 \times$ 

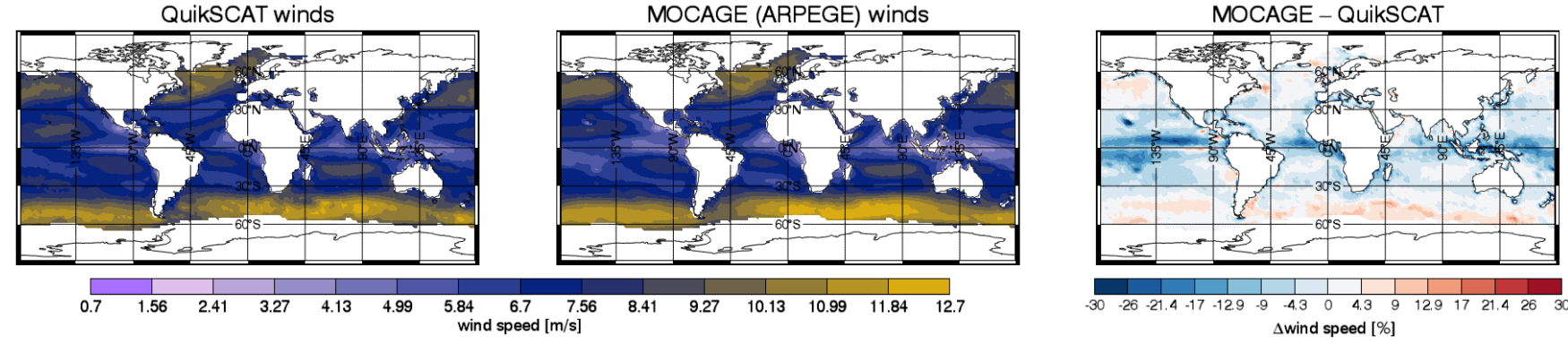

Figure 1. Mean annual surface winds for 2007: left - QuikSCAT measurements, middle - ARPEGE analysis, and right - their relative difference.

$10^{-11}$, and $C_{4}=-1.424$ are constants valid for sea salt particles. The particle sizes are assumed to be in an equilibrium corresponding with the ambient relative humidity. The hygroscopic growth affects optical properties and deposition of sea salt aerosols, and Eq. (21) is also used to calculate these effects. The Gerber (1985) relation is not accurate for high relative humidity (Fan and Toon, 2011). Thus, we limit relative humidity to $95 \%$ to avoid unrealistic optical depths and deposition. In SIM2, the sea salt temperature used in Eq. (20) is implemented from the Reynolds data set (Reynolds et al., 2002).

Due to the $u_{10}^{3.41}$ wind dependency (Eq. 20), the sea salt source function is very sensitive to the quality of the wind field in the model. To assess winds used in the CTM MOCAGE we compared the surface wind speed of the ARPEGE analysis with satellite surface wind measurements from the SeaWinds scatterometer located on the QuikSCAT satellite. Spaceborne scatterometers are calibrated to measure the so-called equivalent neutral stability wind defined as the wind that would be observed under neutral stability conditions or atmospheric stratification. The equivalent neutral stability wind speed is very similar to actual wind speed, but they are not the same. The differences between the two can be as large as $0.5 \mathrm{~m} \mathrm{~s}^{-1}$ (Bourassa et al., 2003). We use the monthly level 3 (L3) QuikSCAT data set for 2007 with a resolution of $1^{\circ} \times 1^{\circ}$ (Bourassa et al., 2003), which is regridded to the MOCAGE $2^{\circ} \times 2^{\circ}$ resolution and averaged to get a mean annual wind field. The comparison of the mean 2007 wind fields from ARPEGE and QuikSCAT are presented in Fig. 1. The two fields have a very good agreement, with relative differences that are their strongest $(\sim 20 \%)$ in the regions dominated by low wind speeds. The differences are very similar to what Chelton and Freilich (2005) found by comparing ECMWF and QuikSCAT fields. A part of the disagreements can be explained by the differences between the equivalent neutral stability wind, which is observed by the scatterometer, and the actual wind, which is represented in the NWP (numerical weather prediction) analyses, and the fact that scatterometer retrievals typically overestimate buoy observations for relatively low wind speeds $\left(<4 \mathrm{~m} \mathrm{~s}^{-1}\right)$ (Bentamy et al., 1999; Chelton and Freilich, 2005). It should also be noted that Chelton (2005) remarked that NWP models do not represent well the influence of SST on low-speed winds over warm waters that could lead to a model underestimation in these regions.

\subsubsection{Desert dust emission schemes}

The emission of mineral dust particles in arid zones depends on the surface characteristics and wind intensity. If the wind friction velocity is larger than the erosion threshold velocity for a given particle size and soil properties, particles can be emitted into the atmosphere (e.g. Zhao et al., 2006). A desert dust emission scheme takes into account all of the main processes involved: achievement of the erosion threshold, saltation where particles start to move horizontally, and sandblasting where the fine particles are released from soil aggregates into the atmosphere due to impacts between the saltating particles and the surface.

In MOCAGE, two emission schemes have been implemented: the first one for African and Arabian deserts (Marticorena et al., 1997), and the second one for deserts in Asia (Laurent et al., 2006). The Marticorena et al. (1997) scheme covers Africa, Arabia and the Middle East (13$36^{\circ} \mathrm{N}, 17^{\circ} \mathrm{W}-77^{\circ} \mathrm{E}$ ) with a resolution of $1^{\circ} \times 1^{\circ}$. The input soil properties and aerodynamical surface parameters are based on available pedological, topographical, geological and climatological data and analysis (Marticorena et al., 1997; Callot et al., 2000). The main sources were from the French National Geographic Institute (IGN) and Soviet topographic maps. Laurent et al. (2006) developed the emission scheme for north-eastern Asia that includes all arid areas in the region $35.5-47^{\circ} \mathrm{N}, 73-125^{\circ} \mathrm{E}$. Typical soil characteristics are derived from soil samples (Mei et al., 2004) and statistically analysed and extrapolated to all known deserts in the domain. Aerodynamical surface parameters are determined from POLDER-1 surface bidirectional reflectance observations with a resolution of $0.25^{\circ} \times 0.25^{\circ}$.

Regarding the desert dust emission schemes in the different model configurations, in SIM2 compared to SIM1, we changed the wind fields interpolation method and the initial size distribution. 
In SIM1, ARPEGE wind analysis is rebinned to the resolution of the emission schemes with the nearest-neighbour interpolation. In SIM2 we also take into account all adjacent gridboxes with the bilinear interpolation.

The initial emitted size-distribution is a three-mode lognormal distribution composed of fine, accumulation and coarse modes. The size distribution used in SIM1 has the number median diameters $r_{1}=1.7 \times 10^{-6} \mathrm{~m}, r_{2}=6.7 \times$ $10^{-6} \mathrm{~m}$, and $r_{3}=14.2 \times 10^{-6} \mathrm{~m}$; geometric standard deviations $\sigma_{1}=1.7, \sigma_{2}=1.6$, and $\sigma_{3}=1.5$; and mass fractions frac $_{1}=0.3$, frac $2=0.4$, and $\mathrm{frac}_{3}=0.3$. In this study we modified the size distribution following Alfaro et al. (1998) and Crumeyrolle et al. (2011), and in SIM2 our distribution is shifted towards smaller sizes with number median diameters $r_{1}=6.4 \times 10^{-7} \mathrm{~m}, r_{2}=3.45 \times 10^{-6} \mathrm{~m}$, and $r_{3}=$ $8.67 \times 10^{-6} \mathrm{~m}$; the standard deviations and the mass fractions are the same as above.

\section{Observations}

To evaluate the performance of the model we use largescale satellite observations, ground-based photometer data and in-situ surface measurements. The MODIS (Moderateresolution Imaging Spectroradiometer) instruments observe atmospheric aerosols aboard Terra (since 2000) and Aqua (since 2002) from complementary sun-synchronous orbits. We use MODIS aerosol optical depth Collection 5 retrievals at $550 \mathrm{~nm}$ from Terra and Aqua that have predicted uncertainties of $\Delta \tau= \pm(0.03+0.05 \tau)$ over oceans and $\Delta \tau=$ $\pm(0.05+0.15 \tau)$ over land (Remer et al., 2005). We start with good-quality global level 3 (L3) daily MODIS data (QAweighted products) and perform an additional quality control by rejecting all gridboxes with less than five level 2 (L2) observations per a L3 gridbox and more than a $50 \%$ cloud fraction. To combine Terra and Aqua observations and to regrid from the original L3 $1^{\circ} \times 1^{\circ}$ grid to the MOCAGE $2^{\circ} \times 2^{\circ}$ grid we weight data by considering the number of L2 observations in each L3 gridbox. The data are processed in this manner to minimize the number of observations that are cloud contaminated and those with statistically low confidence, which often artificially increase AOD (Remer et al., 2008; Zhang et al., 2005; Koren et al., 2007).

AERONET (Aerosol Robotics Network) measures ground-based AOD from hundreds of automated stations with an accuracy of \pm 0.01 (Holben et al., 1998). We use L2 daily data from different stations and interpolate it in logarithmic space to $550 \mathrm{~nm}$ (to harmonize wavelengths between different stations and with the model) by using available neighbouring wavelengths: $440,500,675$, and $870 \mathrm{~nm}$.

Carrer et al. (2010) applied a multi-temporal approach to SEVIRI (Spinning Enhanced Visible and InfraRed Imager) geostationary observations to derive surface and aerosol properties simultaneously. They retrieved AOD over land us- ing directional and temporal analysis of the signal, as opposed to spectral and spatial analysis done in MODIS retrievals (Ichoku et al., 2005). The data cover the SEVIRI field of view with a selected resolution of $1^{\circ} \times 1^{\circ}$, which is later regridded to the MOCAGE resolution. SEVIRI AOD observations are considered only if their relative uncertainty is estimated to be less than $75 \%$.

The EMEP (European Monitoring and Evaluation Programme - Cooperative programme on the long-range transmission of air pollutants in Europe) observation network consists of background stations and provides particulate matter measurements $\left(\mathrm{PM}_{2.5}\right.$ and $\left.\mathrm{PM}_{10}\right)$ throughout Europe (Tørseth et al., 2012). We use measurements from the EMEP stations where primary aerosols have a dominant effect. The considered stations have hourly or daily measurement frequencies.

\section{Experiment design}

We conduct our experiment to test the performance of the model in two main stages. First, we compare model outputs with observations. We define two main model configurations used as reference simulations and compare them with observations to evaluate the overall impact of the model updates. The reference simulations are called SIM1 and SIM2 and their configurations are presented in Table 2. SIM1 uses the configuration of MOCAGE with the current parameterizations while in SIM2 we use the updated parameterizations. Second, we evaluate the sensitivities of our results to the individual modules updates introduced in this study. To emphasize the separate effects of the parameterization updates, we have implemented different configurations based on the reference simulations. We separately analyse the impact of these updates on the emissions, sedimentation and wet scavenging (in simulations SIM2_EMI, SIM2_SED and SIM2_WDEP in Table 2), and we study the introduction of thermophoresis, diffusiophoresis and electric effects in the below-cloud scavenging (simulation SIM2_BCPLUS in Table 2). The simulations cover the globe for the year 2007 and use dynamics from 3-hourly meteorological fields from ARPEGE analyses downgraded to a resolution of the model $\left(2^{\circ} \times 2^{\circ}\right)$. We have only primary aerosols in the model. Thus, to compare the model outputs with observations, we focus on the regions where primary aerosols dominate the aerosol optical depth field, and on strong, high-concentration aerosol events near the sources where we can presume that the contribution of other aerosols is minimal. Inspecting the averaged quantities (annual budget, burden, lifetime, emissions, depositions) allow us to evaluate the relative importance of different parameterizations and processes. 

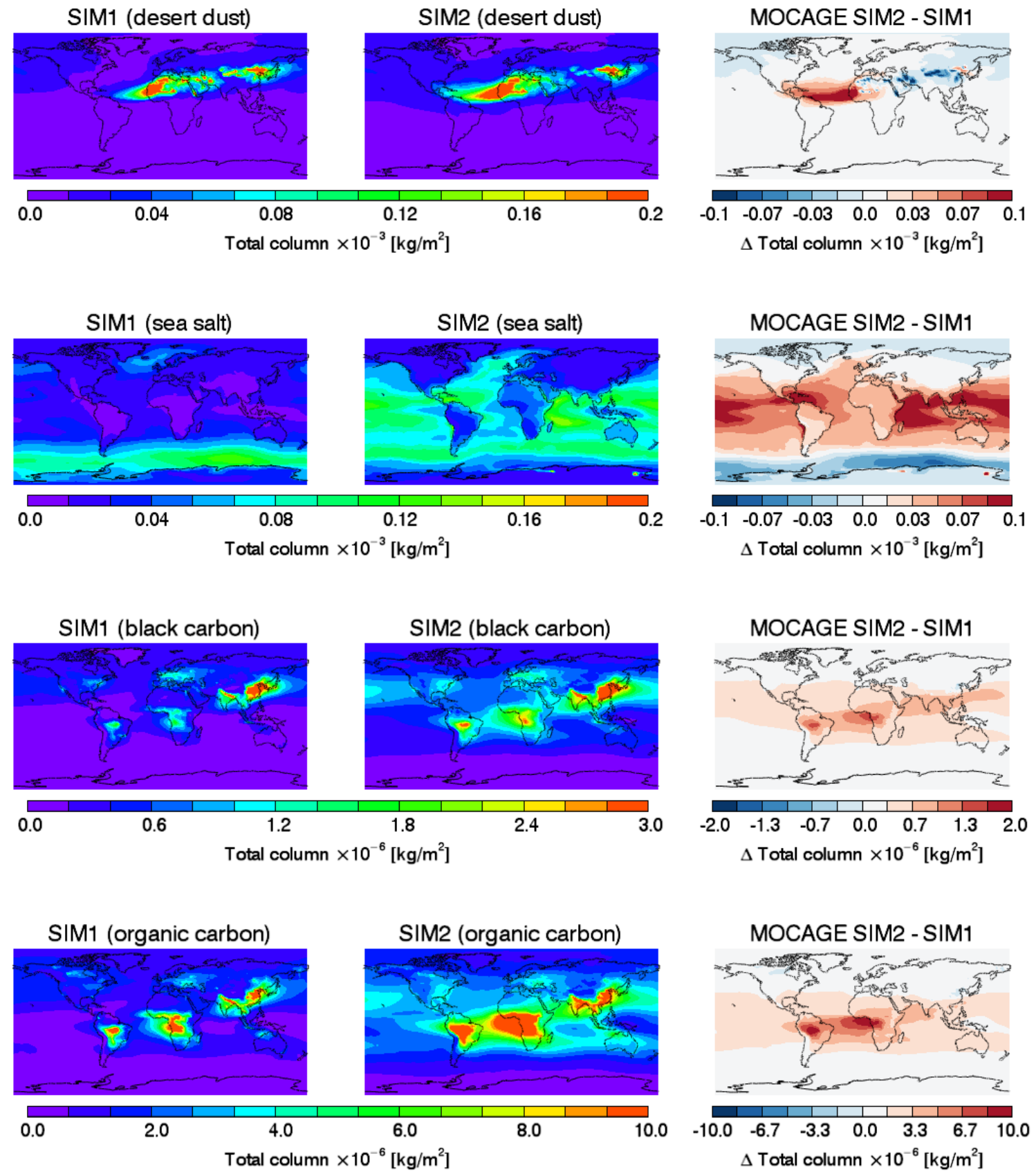

Figure 2. The geographic distribution of the mean annual burdens of all aerosol species in the CTM MOCAGE: for SIM1 on the left, for SIM2 in the middle, and their difference on the right.

\section{Results}

In this section we evaluate MOCAGE SIM1 and SIM2 output and compare it to independent data. Figures 2 and 3 present the effects of the model updates, by showing horizontal geographical and vertical zonal distribution of aerosol species in MOCAGE for the SIM1 and SIM2 simulations. As shown in Fig. 2, the changes to the model in SIM2 compared to SIM1, resulted in less desert dust aerosols near sources in Asia and northern Africa, but more in the south-eastern part of the Sahara. Also, more aerosols are transported over the Atlantic, with the long-range transport eased by the shift in the initial size distribution towards smaller sizes in SIM2 (Sect. 3.4.2). Sea salt aerosols are more abundant globally in SIM2 compared to SIM1. Over cold waters, especially over southern oceans, we note a decrease and over warm waters an increase in the sea salt burden. This shift is mainly due to the introduction of the SST dependency in the sea salt emission scheme 

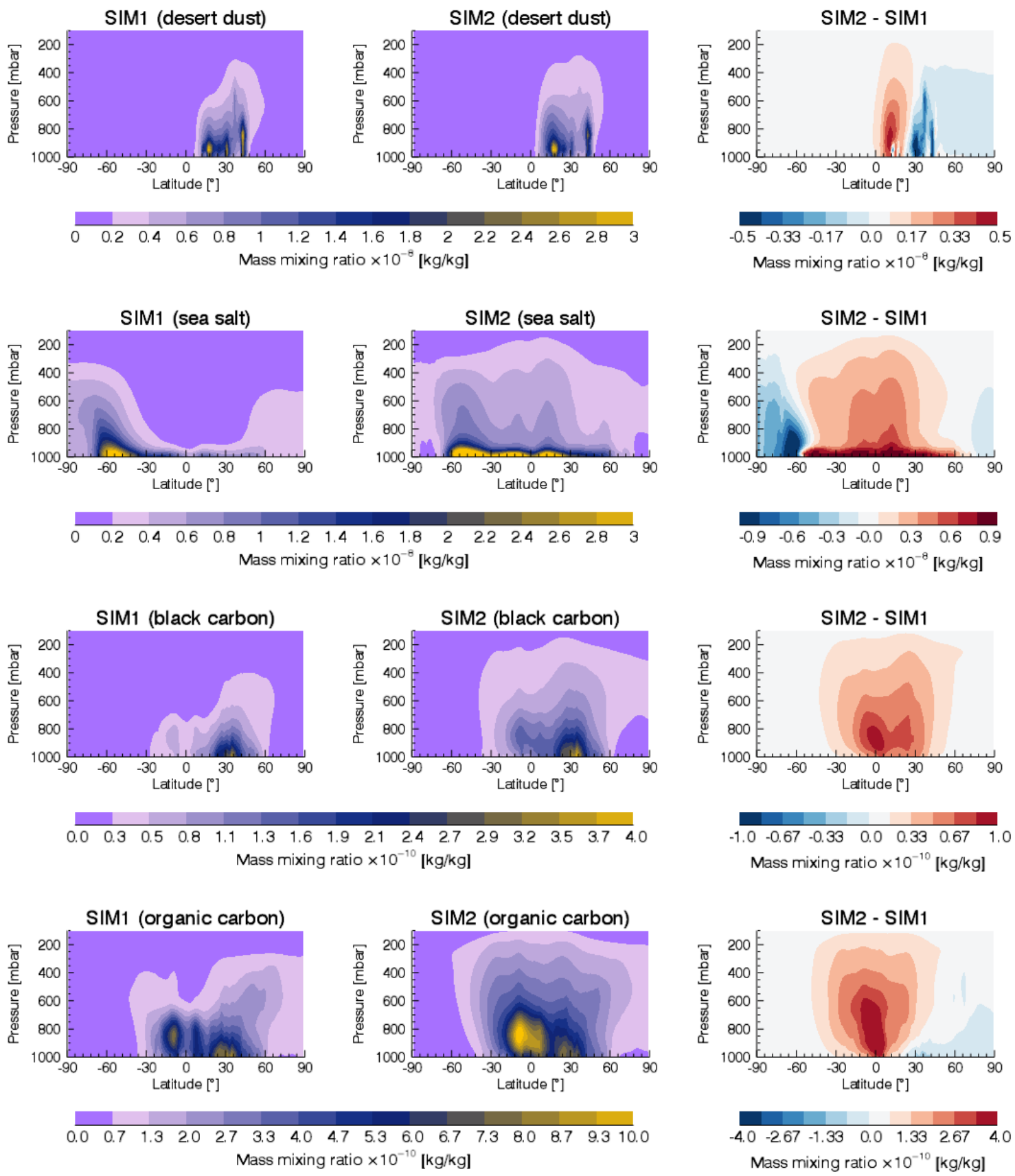

Figure 3. The annual and zonal mean vertical profiles of mass mixing ratios of all aerosol species in the CTM MOCAGE: for SIM1 on the left, for SIM2 in the middle, and their difference on the right.

in SIM2. Having the black carbon and organic carbon emissions quite similar in SIM1 and SIM2, the differences between SIM1 and SIM2 reflect mainly the changes in the wet deposition scheme. The increase in their burden in SIM2 is the outcome of the weaker wet deposition in total in SIM2 than in SIM1. Figure 3 confirms these findings and, although a number of effects influence the mass mixing ratios, one can see that the updates generally produced more desert dust and sea salt aerosols toward higher altitudes. Regarding black and organic carbon aerosols, Fig. 3 shows their higher concentrations in the free troposphere in SIM2 than in SIM1. This is the result of the weaker wet deposition in SIM2 than in SIM1 and of the shift in the wet deposition vertical distribution by having a weaker below-cloud scavenging and a stronger incloud scavenging in SIM2 compared to SIM1.

In Fig. 4, SIM1 and SIM2 AOD fields are compared with global yearly averaged MODIS AOD. Model AOD values are only sampled in the case of available MODIS observations 
Table 3. Number of observations, correlation $(\rho)$, modified normalized mean bias (MNMB) and fractional gross error (FGE) between observations (MODIS and AERONET) and SIM1/SIM2. The number of MODIS observations includes the number of considered L3 gridboxes, and the corresponding number of L2 observations. EMEP observations are of hourly or daily frequency. MODIS regions correspond to Fig. 6a-c, and AERONET sites correspond to Fig. 7a-f.

\begin{tabular}{|c|c|c|c|c|c|c|c|c|}
\hline \multirow[b]{3}{*}{ MODIS } & & & \multicolumn{3}{|c|}{ SIM1 } & \multicolumn{3}{|c|}{ SIM2 } \\
\hline & \multicolumn{2}{|c|}{ No. obs. } & $\rho$ & MNMB & FGE & $\rho$ & MNMB & FGE \\
\hline & L3 & $\mathrm{L} 2$ & & & & & & \\
\hline African dust outflow region & 84272 & $8.6 \times 10^{6}$ & 0.76 & -1.009 & 1.009 & 0.797 & -0.222 & 0.268 \\
\hline Tropical Pacific & 91322 & $9.8 \times 10^{6}$ & 0.647 & -0.715 & 0.716 & 0.689 & 0.267 & 0.268 \\
\hline South Pacific* & 23687 & $3.0 \times 10^{6}$ & 0.334 & 0.652 & 0.676 & 0.363 & 0.158 & 0.278 \\
\hline AERONET & & L2 & & & & & & \\
\hline Tenerife Santa Cruz & & 033 & 0.553 & -0.527 & 0.663 & 0.687 & 0.192 & 0.447 \\
\hline Cabo Verde & & 389 & 0.587 & -1.019 & 1.034 & 0.632 & -0.216 & 0.449 \\
\hline Nauru & & 040 & 0.074 & -1.508 & 1.519 & 0.217 & 0.513 & 0.564 \\
\hline Tahiti & & 328 & 0.091 & -0.697 & 0.989 & 0.277 & 0.805 & 0.813 \\
\hline Amsterdam Island & & 933 & 0.204 & 0.703 & 0.778 & 0.269 & 0.501 & 0.582 \\
\hline Crozet Island & & 361 & 0.076 & 1.161 & 1.168 & 0.181 & 0.644 & 0.723 \\
\hline \multicolumn{9}{|l|}{ EMEP } \\
\hline Hyytiälä, FI (P2.5) & & 140 & 0.059 & -1.236 & 1.24 & 0.545 & -0.778 & 0.785 \\
\hline Lille Valby, DK (P2.5) & & 327 & 0.041 & -1.02 & 1.041 & 0.042 & -0.262 & 0.518 \\
\hline Ayia Marina, CY (P10) & & 302 & 0.266 & -1.787 & 1.787 & 0.312 & -0.374 & 0.602 \\
\hline Auchencorth Moss, GB (P10) & & 428 & 0.064 & -1.003 & 1.471 & 0.197 & -0.706 & 1.106 \\
\hline Zingst, DE (P10) & & 333 & -0.121 & -0.904 & 0.939 & -0.138 & 0.350 & 0.70 \\
\hline
\end{tabular}

* Statistics calculated excluding the winter months because of very few observations.

on a particular day. Overall, SIM2 shows a significant improvement over SIM1 in terms of AOD. The modified normalized mean bias is decreased from 0.42 to 0.10 and the correlation is improved from 0.06 to 0.32 (Figs. 4, 5; Table 3). The improvement is especially apparent in mid- to high-latitude Southern Hemisphere oceans (where the modified normalized mean bias is lowered from 0.65 to 0.16 ) and the African dust outflow region (the modified normalized mean bias improved from -1.01 to -0.22 ). Near coasts, where the influence from the land is stronger, both model simulations underestimate AOD. This could be due to the absence of secondary aerosols in the model. The effect is more evident near south-eastern Asia, India, the Arabian Peninsula and in the Gulf of Guinea, and is less pronounced in SIM2 due to the changes in primary aerosol parameterizations. The cause of discrepancy over the Gulf of Guinea is not clear and a similar pattern is observed by Jaeglé et al. (2011) in the GEOS-Chem model. In MOCAGE, it could be due to the missing secondary aerosols, the insufficient biomass burning aerosol concentration or possibly the cloud contamination in the MODIS data. Another possibility that is less likely is the inaccurate sea salt emissions due to possible wind errors in the ARPEGE analysis; however, considering the low wind speeds in the region (Fig. 1) we do not expect a lot of sea salt particles. In the tropical oceans, compared to MODIS, model
AOD shifted from a negative bias in SIM1 to a positive bias in SIM2. The results for SIM2 were significantly better, but the model still overestimates AOD with discrepancies that are larger than the MODIS expected error.

The relationship between model simulations and observations are presented in Fig. 5. This figure confirms the improvement in the AOD field in SIM2 compared to SIM1, but with discrepancies with observations visible in both simulations. As we performed a strong quality control of the MODIS data, we presume that these discrepancies are related to the model performance. Having in mind also Fig. 4, SIM1 (Fig. 5a) shows strong signatures of overestimated sea salt AOD, a lack of secondary aerosols and an underestimation of desert dust particles. SIM2 (Fig. 5b) has significantly better statistics, a better correlation and smaller standard deviation relative to the observations, but still displays the strong signature of the missing secondary aerosols.

Figure 6 presents the temporal variability comparison of model simulations with MODIS observations over the selected regions, where primary aerosols dominate the AOD throughout the year and which are large enough to cover a statistically meaningful number of observations (usually thousands of observations per day). This figure confirms the positive effect due to the updates in the model parameterizations (statistics of Fig. 6 shown in Table 3). In the Saharan 


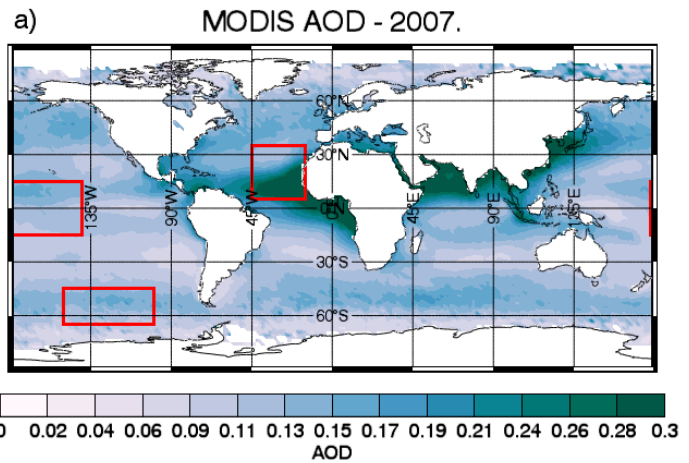

b)

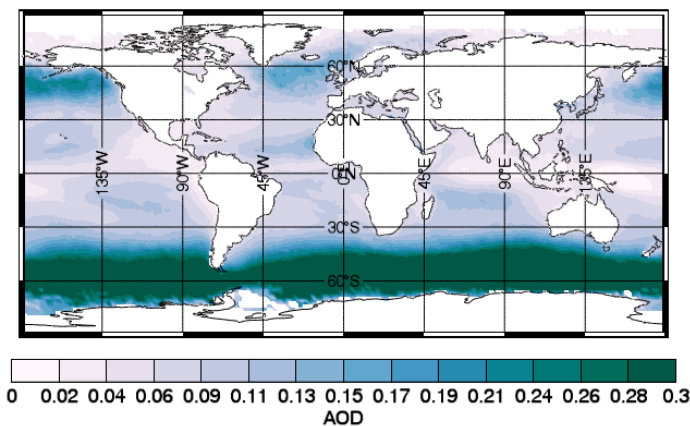

.

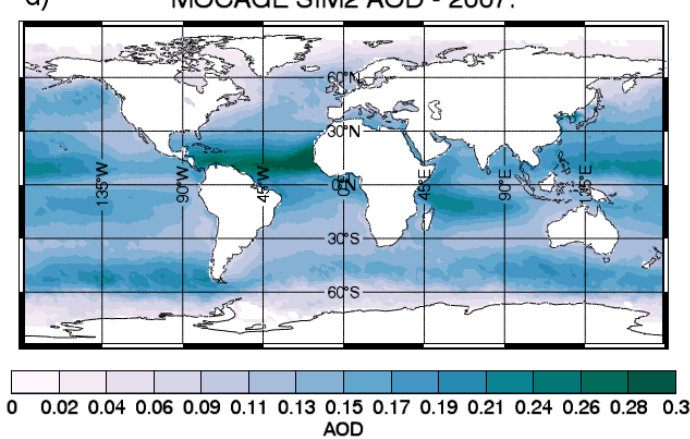

c) MOCAGE SIM1 minus MODIS AOD - 2007.

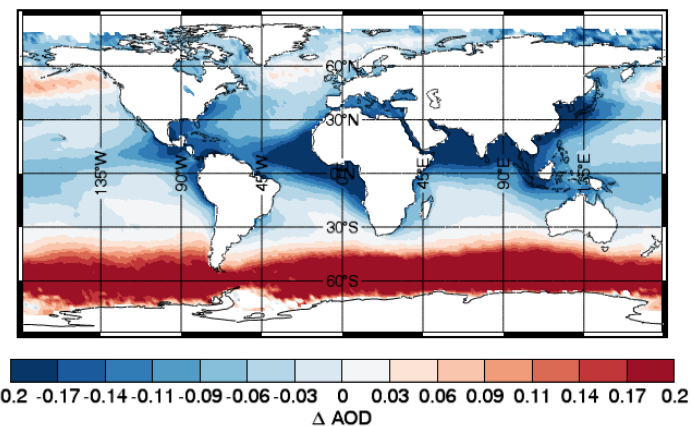

e) MOCAGE SIM2 minus MODIS AOD - 2007.

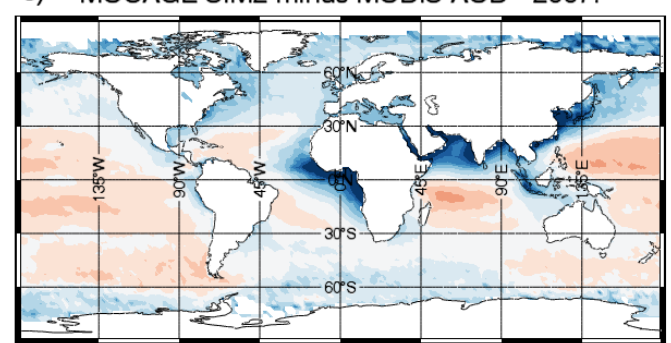

$\begin{array}{cccccccccccc}-0.2 & -0.17-0.14-0.11-0.09-0.06-0.03 & 0 & 0.03 & 0.06 & 0.09 & 0.11 & 0.14 & 0.17 & 0.2\end{array}$

Figure 4. Global, mean aerosol optical depth at $550 \mathrm{~nm}$ for the year 2007 from MODIS (Aqua + Terra) (a), SIM1 (b), SIM2 (d), and the difference between MODIS observations and model simulations (c, e). The descriptions of the model simulations are in Table 2 . The boxes in panel (a) correspond to the regions used in Fig. 6.

desert dust outflow region over the Atlantic (Fig. 6a), SIM2 agrees better with MODIS than SIM1, but with some underestimation of AOD in both simulations. We improved the intensities of the stronger dust events and overall correlation, and lowered the bias. Over the tropical waters of the central Pacific, SIM2 shows a slight statistical improvement (Fig. 6b): while SIM2 overestimates, SIM1 underestimates AOD. In the high-wind South Pacific region (Fig. 6c), SIM2 greatly improves the AOD values and reduces the bias. Correlations between the observations and the simulated AOD are smaller than in the other regions, which is possibly due to wind errors present in the ARPEGE analysis for this remote part of the world. However, by taking into account the whole year data, SIM1 correlates better with MODIS than SIM2. The cause is a minimum in AOD in the Southern Hemisphere winter visible in the MODIS data, which is not present in the model. The noted minimum in the data is determined by only a small number of satellite observations (there are even days without observations over the whole region because of high cloudiness). Thus, statistical confidence in the observations over that period is low. In the model, winds (Fig. 1) and sea surface temperature in this region do not show important systematic errors and are therefore probably not responsible for the discrepancy. If we exclude the effect of the observed winter minimum from our analysis, correlations in SIM2 are superior to SIM1 (0.33 in SIM1, 0.36 in SIM2), which demon- 
a)
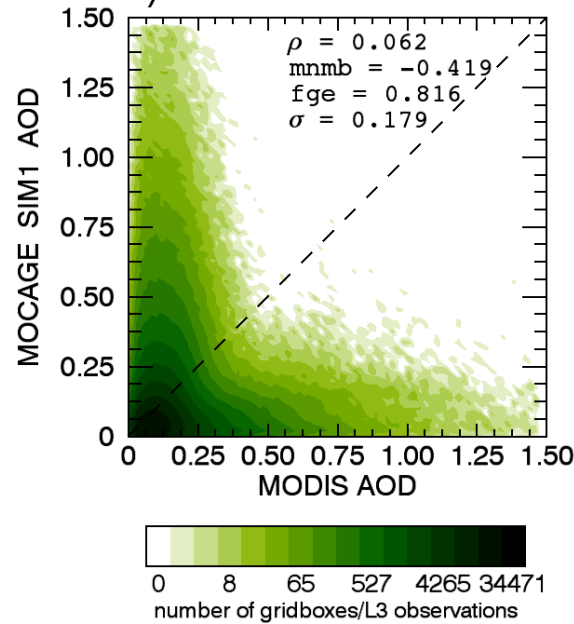

b)

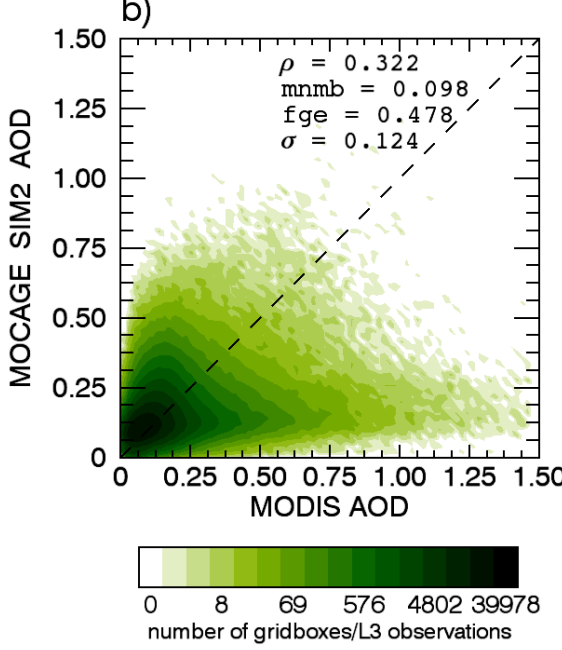

Figure 5. Scatterplots of aerosol optical depths from MODIS and the simulations: SIM1 (a), SIM2 (b). Scatterplots are contoured according to the number of the points in them. Each point in the scatterplot presents MODIS L3 observed AOD and the corresponding modelled AOD. In each panel, correlation $(\rho)$, modified normalized mean bias (MNMB), fractional gross error (FGE) and standard deviation $(\sigma)$ are noted The descriptions of the model simulations are in Table 2.

strates the improvement in the representation of aerosols in this part of the globe.

We also compared the model AOD with the independent data set from AERONET for 2007 (Fig. 7). AERONET data are very accurate and often used for the validation of satellite data (Remer et al., 2005; Kahn et al., 2005; Schuster et al., 2012). However, the horizontal representativity of AERONET data is much smaller compared to that of satellite data. The data are less adapted to make comparisons with the model than satellite data - it is localized in a single spot for each station compared to the $2^{\circ} \times 2^{\circ}$ model data. It may be preferable to do multi-year analysis to improve statistics since some stations do not have the whole year record, and observations are especially scarce in the wintertime. For our study, we chose the stations with available observations where primary aerosols dominate AOD. The AERONET observations confirmed the findings from the comparison with MODIS (Fig. 7, with statistics shown in Table 3): SIM2 reduced the AOD underestimation in the African dust outflow region (stations on Tenerife and Cabo Verde), reduced sea salt overestimation in mid- and high-latitude regions (Amsterdam Island and Crozet Island), and had a minor impact on the absolute value of the bias - but changed its sign - over tropical regions (Nauru and Tahiti). We noted that AERONET stations on the oceanic islands show smaller AOD values than MODIS.

In Fig. 8 we compare the model simulation with the independent data from SEVIRI. We used the daily averaged only-land SEVIRI data (Carrer et al., 2010) to analyse an AOD field over Europe on a day (23 May 2007) when several strong primary aerosol events dominated the AOD field: several desert dust plumes visible over southern and central
Europe, and sea salt aerosols to the north of the British Isles. In both model simulations we see the same AOD features, but they differ in intensity. The location and extent of the features in the model correspond well with the SEVIRI field, except that the desert dust plume over eastern Europe in the model is located more to the south. The AOD values in SIM2 are much closer to the SEVIRI data than in SIM1. Low background AOD values in the model reveal a systematic underestimation over continents. This could be due to an absence of secondary aerosols.

Besides AOD observations, we assess the MOCAGE performance with the particulate matter measurements from the EMEP surface network. When considering the EMEP network, the majority of stations are in or near urban zones where the signature of secondary aerosols is strong. Therefore, we use the measurements from selected stations which are chosen so that their locations are near coasts where usually sea salt aerosols dominate or in sites far from the urban zones. Figure 9 and Table 3 show how SIM1 and SIM2 compare against EMEP measurements from the selected stations. The comparison shows slight to significant differences due to the model updates, and confirms the overall improvement to the model performance.

Table 4 shows how the MOCAGE simulations compare to data from the AeroCom model inter-comparison (http: //aerocom.met.no/, Textor et al., 2006, 2007). AeroCom data are not based on observations but is an independent data set which indicates how MOCAGE relates to performances of other models. Values from SIM2 compare better to AeroCom ranges, by improving several parameters over SIM1. Emitted quantities fit better in SIM2 and there is an improvement in desert dust and sea salt lifetimes as well. Black carbon emis- 
Table 4. Globally averaged annual burden, lifetime and emissions in SIM1 and SIM2 for individual aerosols species (DD - desert dust, SS - sea salt, BC - black carbon), compared to data from the AeroCom project (Dentener et al., 2006; Textor et al., 2006). For a description of model simulations, see Table 2 .

\begin{tabular}{|c|c|c|c|c|c|c|c|c|c|}
\hline & \multicolumn{3}{|c|}{ SIM1 } & \multicolumn{3}{|c|}{ SIM2 } & \multicolumn{3}{|c|}{ AeroCom } \\
\hline & DD & SS & $\mathrm{BC}$ & $\mathrm{DD}$ & SS & $\mathrm{BC}$ & DD & SS & $\mathrm{BC}$ \\
\hline Burden (Tg) & 9.66 & 9.70 & 0.24 & 11.2 & 34.1 & 0.34 & $19.2 \pm 40 \%$ & $7.52 \pm 54 \%$ & $0.24 \pm 42 \%$ \\
\hline Lifetime (days) & 1.0 & 3.0 & 10.0 & 2.9 & 1.5 & 14.2 & $4.1 \pm 43 \%$ & $0.5 \pm 58 \%$ & $7.1 \pm 33 \%$ \\
\hline Emissions $\left(\mathrm{Tg} \mathrm{yr}^{-1}\right)$ & 3476 & 1180 & 8.89 & 1395 & 8274 & 8.82 & 1678 & 7925 & 7.7 \\
\hline
\end{tabular}

Table 5. Globally averaged annual burden, lifetime, emissions, and deposited mass due to wet deposition, dry surface deposition and sedimentation for different aerosol types (DD - desert dust, SS - sea salt, BC - black carbon, OC - organic carbon) in different model simulations to reveal the separate effects of different model updates. For a description of model simulations, see Table 2.

\begin{tabular}{|c|c|c|c|c|c|c|c|c|c|c|c|c|}
\hline & \multicolumn{4}{|c|}{ SIM2_SED } & \multicolumn{4}{|c|}{ SIM2_EMI } & \multicolumn{4}{|c|}{ SIM2_WETDEP } \\
\hline & $\mathrm{DD}$ & SS & $\mathrm{BC}$ & $\mathrm{OC}$ & DD & SS & $\mathrm{BC}$ & $\mathrm{OC}$ & $\mathrm{DD}$ & SS & $\mathrm{BC}$ & $\mathrm{OC}$ \\
\hline Burden $(\mathrm{Tg})$ & 10.9 & 32.4 & 0.34 & 1.74 & 14.4 & 15.5 & 0.45 & 2.92 & 8.9 & 28.0 & 0.24 & 1.21 \\
\hline Lifetime (days) & 2.84 & 1.43 & 14.2 & 19.3 & 1.51 & 4.79 & 16.5 & 19.6 & 2.32 & 1.23 & 10.1 & 13.4 \\
\hline Emissions $\left(\mathrm{Tg} \mathrm{yr}^{-1}\right)$ & 1395 & 8274 & 8.82 & 33.0 & 3476 & 1180 & 9.89 & 40.4 & 1395 & 8274 & 8.82 & 33.0 \\
\hline Dry deposition $\left(\mathrm{Tg} \mathrm{yr}^{-1}\right)$ & 670 & 1912 & 3.23 & 9.71 & 1824 & 344 & 3.29 & 12.4 & 867 & 2605 & 2.8 & 8.1 \\
\hline Sedimentation $\left(\mathrm{Tg} \mathrm{yr}^{-1}\right)$ & 521 & 4742 & 0.01 & 0.06 & 1328 & 318 & 0.01 & 0.08 & 306 & 3715 & 0.01 & 0.05 \\
\hline \multirow[t]{3}{*}{ Wet deposition $\left(\mathrm{Tg} \mathrm{yr}^{-1}\right)$} & 186 & 1576 & 5.53 & 23.2 & 305 & 534 & 6.4 & 27.9 & 184 & 1908 & 6.1 & 25.3 \\
\hline & \multicolumn{4}{|c|}{ SIM2 } & \multicolumn{4}{|c|}{ SIM2_BCPLUS } & & & & \\
\hline & DD & SS & $\mathrm{BC}$ & $\mathrm{OC}$ & DD & SS & $\mathrm{BC}$ & $\mathrm{OC}$ & & & & \\
\hline Burden $(\mathrm{Tg})$ & 11.2 & 34.1 & 0.34 & 1.74 & 11.1 & 33.6 & 0.34 & 1.72 & & & & \\
\hline Lifetime (days) & 2.93 & 1.50 & 14.2 & 19.3 & 2.90 & 1.48 & 14.0 & 19.0 & & & & \\
\hline Emissions $\left(\mathrm{Tg} \mathrm{yr}^{-1}\right)$ & 1395 & 8274 & 8.82 & 33.0 & 1395 & 8274 & 8.82 & 33.0 & & & & \\
\hline Dry deposition $\left(\mathrm{Tg} \mathrm{yr}^{-1}\right)$ & 860 & 2689 & 3.23 & 9.71 & 859 & 2684 & 3.22 & 9.64 & & & & \\
\hline Sedimentation $\left(\mathrm{Tg} \mathrm{yr}^{-1}\right)$ & 317 & 3772 & 0.01 & 0.06 & 317 & 3766 & 0.01 & 0.06 & & & & \\
\hline Wet deposition $\left(\mathrm{Tg} \mathrm{yr}^{-1}\right)$ & 199 & 1759 & 5.53 & 23.2 & 200 & 1771 & 5.6 & 23.2 & & & & \\
\hline In-cloud scav. $(\% / 100)$ & 0.75 & 0.57 & 0.96 & 0.97 & 0.73 & 0.56 & 0.94 & 0.95 & & & & \\
\hline Below-cloud scav. $(\% / 100)$ & 0.25 & 0.43 & 0.04 & 0.03 & 0.27 & 0.44 & 0.06 & 0.05 & & & & \\
\hline
\end{tabular}

sions correspond well to the AeroCom model average. Both SIM1 and SIM2 black carbon burdens are within the AeroCom range, but the lifetime is by a factor of 2 larger in SIM2 than in AeroCom, which could indicate weak wet deposition in the regions of high black carbon concentrations in SIM2. The sea salt burden in SIM2 is larger than in SIM1, but the lifetime is improved in SIM2.

In summary, observations from MODIS, AERONET, SEVIRI and EMEP showed that changes in the aerosol parameterizations improved the model performance. SIM2 shows a significantly better agreement in AOD compared with different types of observations relative to SIM1, and this is confirmed by in situ observations.

\section{Sensitivity to new parameterization components}

The updates to the parameterizations, which are collectively compared to the observations in the section above, have dif- ferent and separate effects on the model results. In this section we analyse separate impacts of the updates by dividing them into the three most important components: changes in emissions of sea salt and desert dust aerosols, in sedimentation of particles, and in wet deposition. In Fig. 10, simulations SIM2_SED, SIM2_EMI, and SIM2_WDEP are compared with the reference SIM2 run. This figure demonstrates that the improvements in the sedimentation make a modest overall change and that the changes to the emissions and wet deposition changes impact the results much more strongly. The total annual sedimentation in SIM2 decreased by $22 \%$, but this change influenced AOD only moderately: the results of the SIM2 and SIM2_WDEP simulations are very similar with the high correlation between them (0.92; Fig. 10a). In the atmospheric surface layer, sedimentation acts in conceit with dry deposition, and the impacts due to the changes to each process tend to compensate one another (Table 5). 

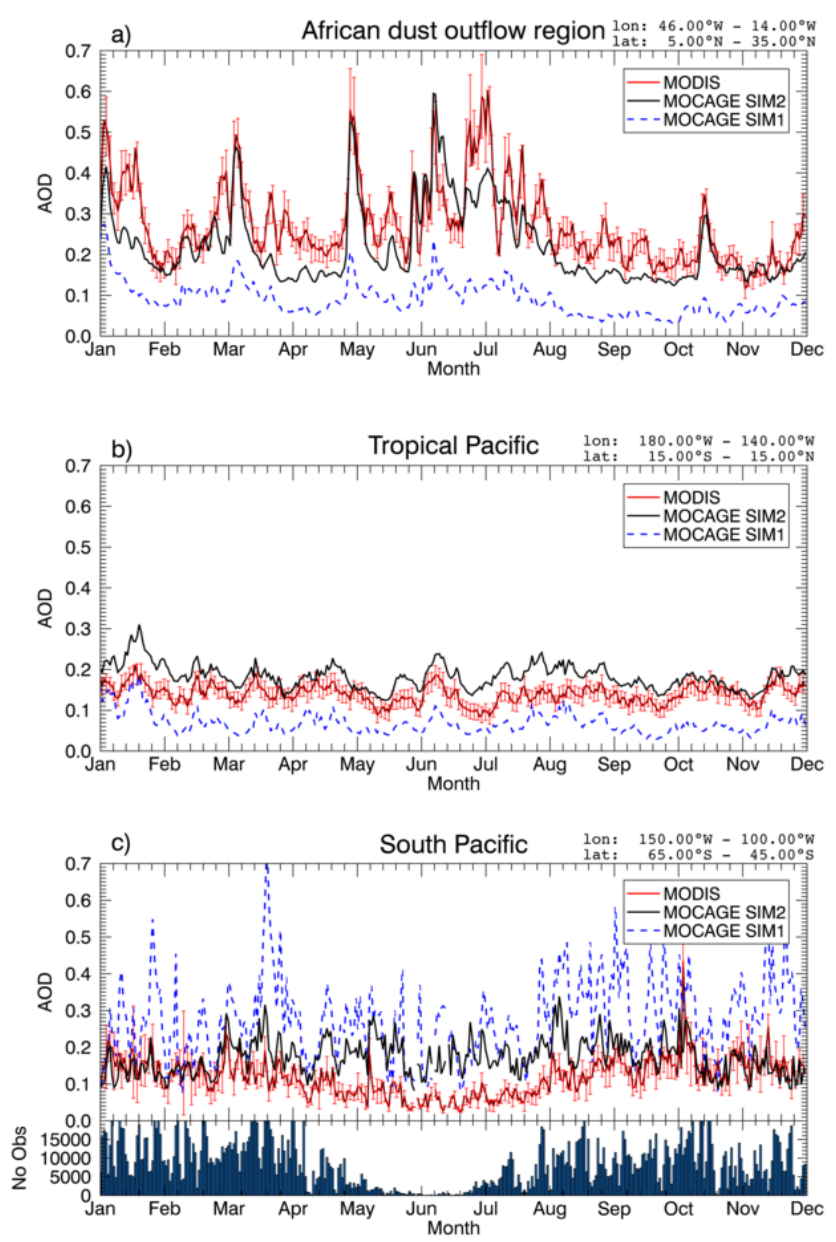

Figure 6. Time series of aerosol optical depth at $550 \mathrm{~nm}$ in 2007 of MODIS (Aqua + Terra) data, SIM1 and SIM2 over (a) the African desert dust outflow region $\left(45-15^{\circ} \mathrm{W}, 5-35^{\circ} \mathrm{N}\right)$, (b) the tropical Pacific $\left(180-140^{\circ} \mathrm{W}, 15^{\circ} \mathrm{S}-15^{\circ} \mathrm{N}\right)$, and (c) the South Pacific (150$\left.100^{\circ} \mathrm{W}, 65-45^{\circ} \mathrm{S}\right)$. The regions are also marked in Fig. $4 \mathrm{a}$. For the South Pacific region, the number of observations over the region is given for each day. Correlation, modified normalized mean bias and fractional gross error for both SIM1 and SIM2 as compared to MODIS data are given in Table 3 . The descriptions of model simulations are in Table 2.

Figure $10 \mathrm{~b}$ presents the changes and major improvements in SIM2 that result from the modifications to the emissions compared to SIM2_EMI. The two distinct populations of points in the scatterplot represent overestimated sea salt particles and underestimated desert dust. In addition, both populations are likely affected by the missing secondary aerosols. In the SIM2 emissions, the desert dust aerosol distribution is shifted towards smaller diameters making the sedimentation process less important for aerosol removal, and consequently their lifetimes are $\approx 50 \%$ longer. The sea salt particle emissions in SIM2 are 7 times larger than in SIM2_EMI, which makes their burden larger in SIM2. Also, their global distribution changed - there are more particles in low and midlat- itudes, which makes their lifetime shorter. Although emitted sea salt quantities hugely vary between different estimates (from 1000 to $30000 \mathrm{Tg} \mathrm{yr}^{-1}$; Lewis and Schwartz, 2004), emissions in MOCAGE are in agreement with the "best" estimate of Lewis and Schwartz (2004) of $5000 \mathrm{Tg} \mathrm{yr}^{-1}$ (estimate uncertainty of the factor of 4) and with AeroCom data (Table 4). Desert dust aerosols are emitted by a factor of 2-3 less in SIM2 than in SIM2_EMI, with the decrease mostly in Asian deserts. The new value agrees better with the AeroCom estimate (Table 4). The change of wind interpolation in the desert dust emission schemes more strongly affected Asian desert dust because of the finer resolution of the scheme and the rougher topography present in this region. The differences between AeroCom and Lamarque et al. (2010) inventories for carbonaceous aerosols did not produce variation.

Figure 10c shows the impact of the wet deposition changes in the model between the SIM2 and SIM2_WDEP simulations. The two simulations are strongly correlated both temporally and spatially but they show important differences in AOD. Compared to SIM2, the below-cloud scavenging is overall stronger in SIM2_WDEP mainly due to the higher precipitating cloud fraction in SIM2_WDEP and missing precipitation re-evaporation (which is only introduced in SIM2). However, the AOD in SIM2 becomes both larger and smaller in different situations; it decreased and increased depending on location with an overall tendency for weaker wet deposition in SIM2 (also shown in Table 5). In tropical regions, where convective systems are the cause of the majority of the scavenging and where re-evaporation has an important impact, aerosol particles are scavenged less in the SIM2 than in SIM2_WDEP (see the subgraph in Fig. 10c). Reevaporation of precipitation effectively mitigates the washout of aerosols and in SIM2 it reintroduced into the atmosphere $9 \%$ of aerosols scavenged by convective precipitation and $10 \%$ of aerosols scavenged by stratiform precipitation. In the midlatitudes, the re-evaporation is less important and the cloud cover is a more important factor. In this region, the changes in the precipitating cloud fraction and other wet deposition updates made the wet scavenging a more powerful process in SIM2 than in SIM2_WDEP (subgraph in Fig. 10c). However, globally, the changes in the wet deposition scheme resulted in $5 \%$ less aerosols scavenged by wet deposition in SIM2 than in SIM2_WDEP. Modifications of the below-cloud scavenging scheme also included additional scavenging processes (thermophoretic, diffusiophoretic and electric charge effects) proposed in the literature (Andronache et al., 2006) and which are introduced in the SIM2_BCPLUS simulation. The additional processes moderately changed the efficiency of the below-cloud scavenging (Table 5). Scavenging increased by $5 \%$, but this only minimally influenced the resulting AOD field. 

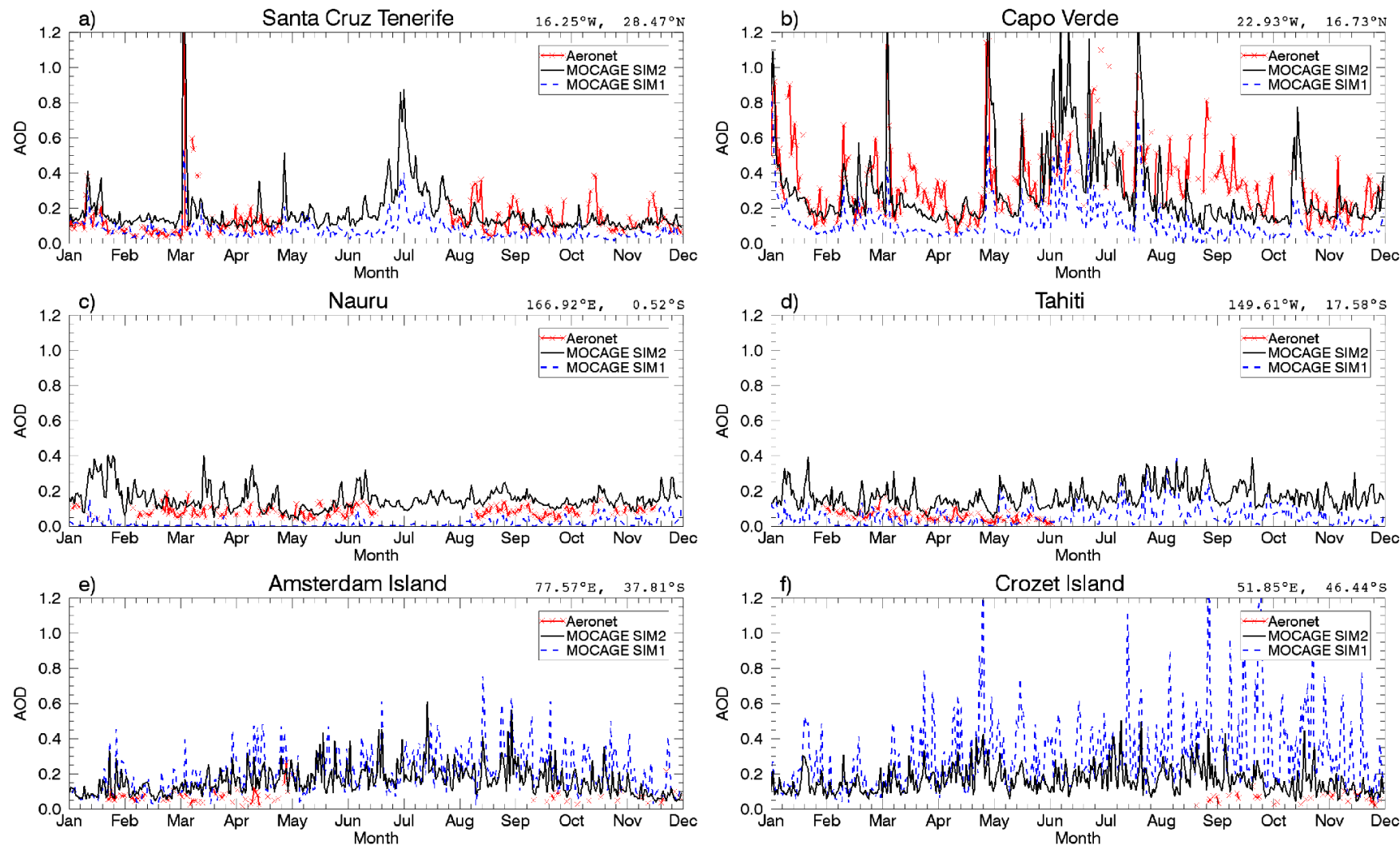

Figure 7. Time series of aerosol optical depth at $550 \mathrm{~nm}$ from the AERONET data, SIM1 and SIM2 for six AERONET stations: Tenerife Santa Cruz $\left(16.25^{\circ} \mathrm{W}, 28.47^{\circ} \mathrm{N}\right)$, Cabo Verde $\left(22.93^{\circ} \mathrm{W}, 16.73^{\circ} \mathrm{N}\right)$, Nauru $\left(166.92^{\circ} \mathrm{W}, 0.52^{\circ} \mathrm{S}\right)$, Tahiti $\left(149.61^{\circ} \mathrm{W}, 17.58^{\circ} \mathrm{S}\right)$, Amsterdam Island $\left(77.57^{\circ} \mathrm{E}, 37.81^{\circ} \mathrm{S}\right)$ and Crozet Island $\left(51.85^{\circ} \mathrm{E}, 46.44^{\circ} \mathrm{S}\right)$. Correlation, modified normalized mean bias and fractional gross error for both SIM1 and SIM2 compared to AERONET observations are given in Table 3. The descriptions of the model simulations are in Table 2.

a) MSG/SEVIRI AOD - 23 May 2007

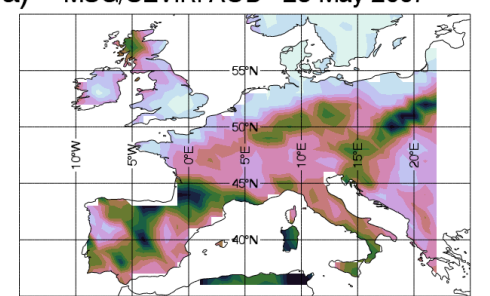

b) MOCAGE SIM1 AOD - 23 May 2007

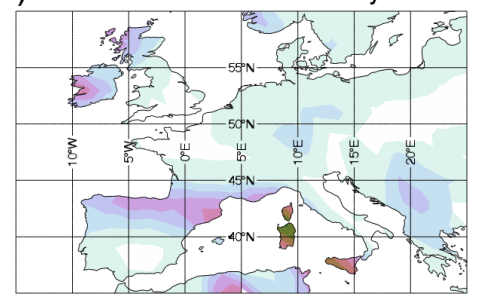

c) MOCAGE SIM2 AOD - 23 May 2007

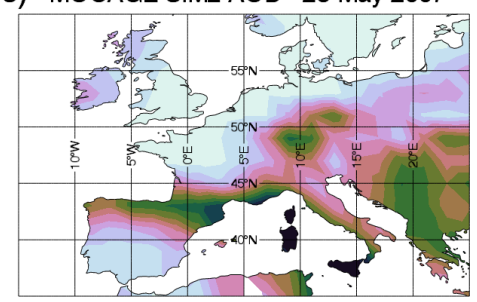

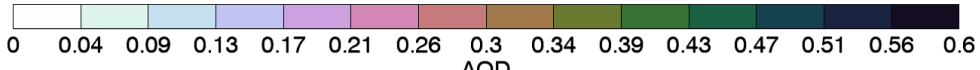

Figure 8. Aerosol optical depth fields over Europe for 23 May 2007 at $550 \mathrm{~nm}$ from SEVIRI (a), SIM1 (b), and SIM2 (c) simulations.

\section{Discussion}

The updated parameterizations improve the aerosol representation in the model and agree better with observations independent from one another. Compared to observations, the updated model still shows some overestimation over the sea salt dominated regions and an underestimation over the Atlantic region affected by the African desert dust outflow. The identified differences in AOD between the model and obser- vations exceed prescribed observation errors and their degree is consistent with the results of other studies: Zhang et al. (2012) with the ECHAM-HAM model compared to MODIS observations, Jaeglé et al. (2011) with the GEOSCHEM model compared to both MODIS and AERONET observations, Su et al. (2013) using the GOCART model compared to the MODIS/MATCH AOD field. Zhang et al. (2012) found that simulated AOD over sea salt regions was overestimated to a similar degree as with MOCAGE, while Saharan 

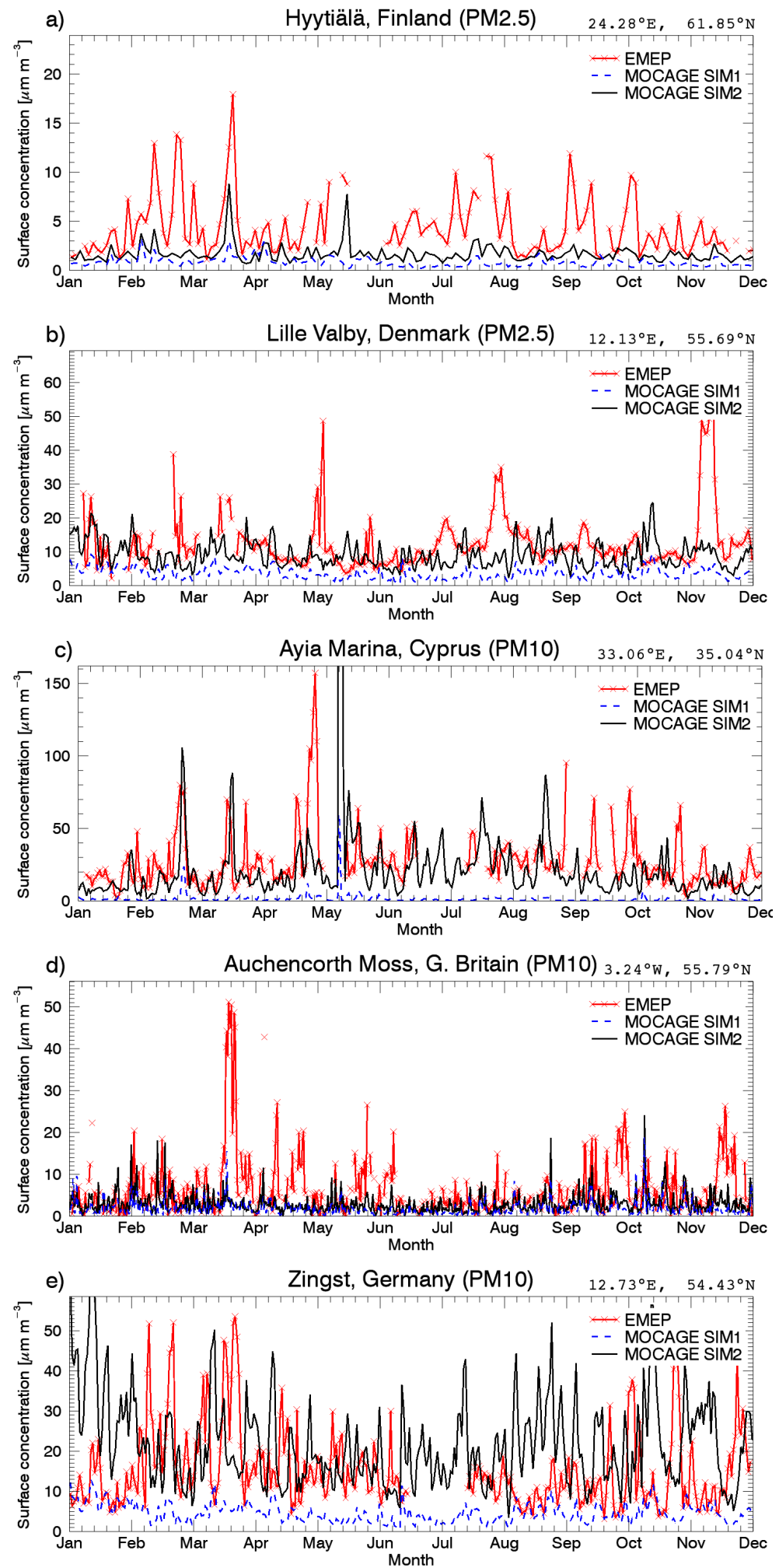

Figure 9. Time series of aerosol PM for 2007 from EMEP data, and for SIM1 and SIM2 for five EMEP stations: Hyytiälä, Finland (PM 2.5 , $\left.24.28^{\circ} \mathrm{E}, 61.85^{\circ} \mathrm{N}\right)$, Lille Valby, Denmark $\left(\mathrm{PM}_{2.5}, 12.13^{\circ} \mathrm{E}, 55.69^{\circ} \mathrm{N}\right)$, Ayia Marina, Cyprus $\left(\mathrm{PM}_{10}, 33.06^{\circ} \mathrm{E}, 35.04^{\circ} \mathrm{N}\right)$, Auchencorth Moss, Great Britain $\left(\mathrm{PM}_{10}, 3.24^{\circ} \mathrm{W}, 55.79^{\circ} \mathrm{N}\right)$ and Zingst, Germany $\left(\mathrm{PM}_{10}, 12.73^{\circ} \mathrm{E}, 54.43^{\circ} \mathrm{N}\right)$. Correlation, modified normalized mean bias and fractional gross error for both SIM1 and SIM2 compared to EMEP observations are given in Table 3. The descriptions of the model simulations are in Table 2. 
a)

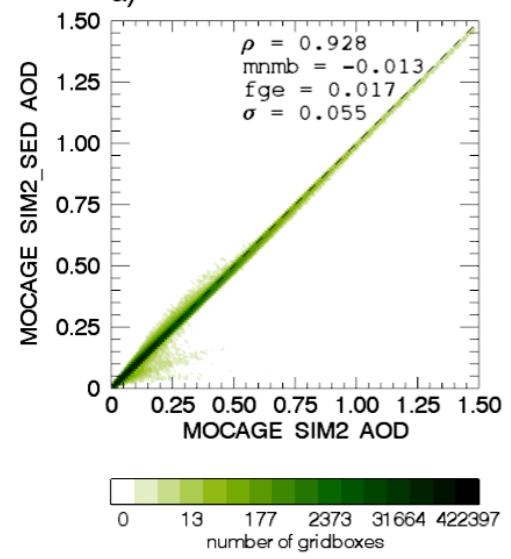

b)
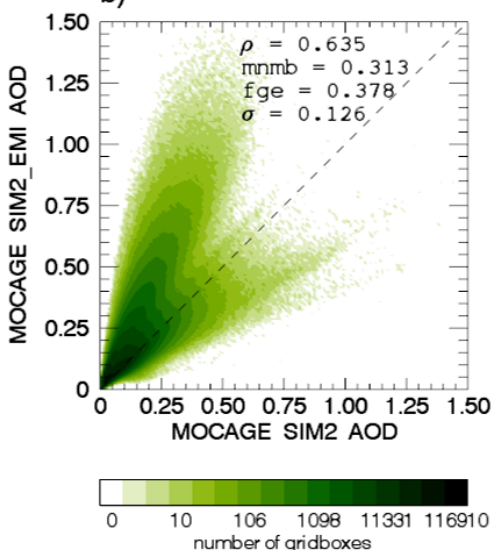

c)
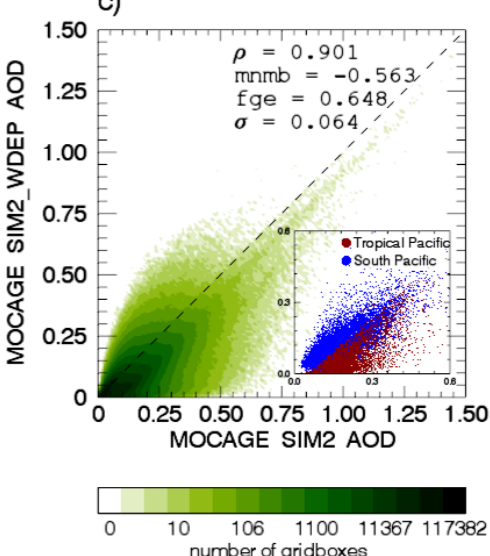

Figure 10. Scatterplots of aerosol optical depth from the model reference run SIM2 and the simulations: SIM2_SED (a), SIM2_EMI (b), and SIM2_WDEP (c). These scatterplots show the impact of different model updates to the model performance and they are contoured according to the number of the points. Each point in the scatterplot presents modelled AOD in two corresponding simulations. In each panel, $\rho$, MNMB, FGE, and $\sigma$ are noted. For the SIM2_WDEP simulation, a subgraph is presented showing the differences between the tropical Pacific and South Pacific regions (regions shown in Fig. 4a). The description of the model simulations is in Table 2.

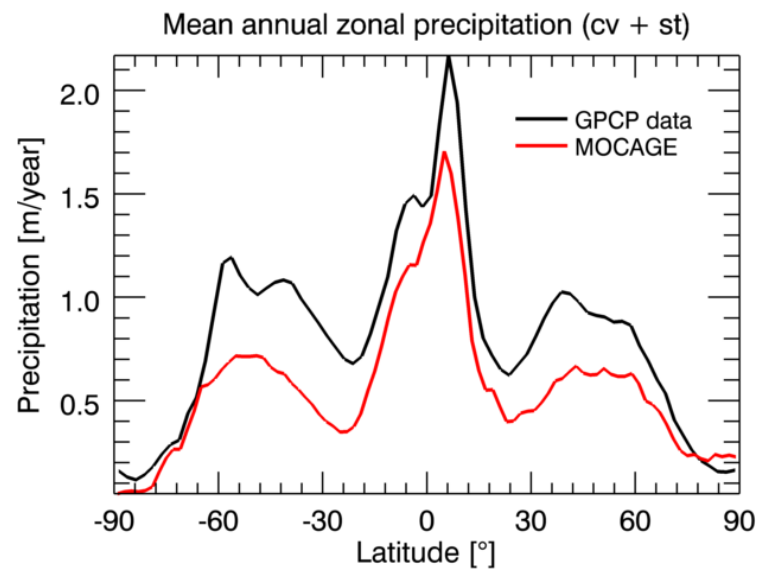

Figure 11. Mean annual zonal precipitation quantity (combined stratiform (st) and convective (cv) precipitation) from GPCP data and MOCAGE.

outflow desert dust AOD was overestimated with an absolute difference of greater than a factor of 2 , as compared to MOCAGE. Jaeglé et al. (2011) found that AOD over sea salt regions of the global oceans was underestimated by less than 0.04 and over the African dust outflow region it was overestimated with the absolute difference greater by a factor of 2-3, as compared to MOCAGE. Su et al. (2013) compared GOCART with the assimilated MODIS/MATCH AOD that was "constrained to a large extent by MODIS" and found that AOD over the sea salt regions was overestimated slightly more than in MOCAGE, and that AOD over the African dust outflow region was underestimated a little less than in MOCAGE.
We noted in the previous paragraph that the present-day state-of-the-art models have similar performance compared to MOCAGE. Regarding this study, the biases could have different causes, and we should concentrate our further model developments to deal with these issues. Concerning desert dust aerosols, the peaks of the most intense desert dust events are well reproduced in MOCAGE, but in days with more moderate dust production we notice weaker model AOD than in the observations. These weaker AOD values over the African dust outflow region were found both near and far from the sources, which hints that emissions of African desert dust may be too small. Wind uncertainties could be important in this region, which could lead to less fugitive sand and dust, or the soil characterization in the scheme might need a refinement (e.g. better resolution, satellite retrieved soil type/properties) (Laurent et al., 2008a, b; Bouet et al., 2012).

The sea salt discrepancy between MOCAGE and observations can possibly be caused by several factors: too high emissions, too weak below-cloud scavenging, and the missing sea salt chemical evolution in the model. First, we examine the possibility that the high sea salt burden results from emissions that are too large. Emitted sea salt quantities are in agreement with the AeroCom model average (Table 4), but the very large range in emissions in AeroCom indicates large uncertainties (Textor et al., 2007). Jaeglé et al. (2011) clearly showed the sea salt emission dependency on sea surface temperature, but their parameterization could be model dependent because they derived it by minimizing the bias of their model relative to in situ observations. Models could vary significantly and it might be necessary to separately fit the parameters of the Jaeglé et al. (2011) function to the individual model employed (which Jaeglé et al., 2011, also noted). This 
idea is supported by results from Spada et al. (2013), who implemented the sea salt function from Jaeglé et al. (2011) in the NMMB/BSC-CTM model and found the sea salt is overestimated in the tropical regions. Still, the parameterization depending on sea surface temperature undoubtedly improved the performance of MOCAGE.

The ratio of wet deposition to the total dry deposition (surface dry deposition + sedimentation) measured on cruise ships is $0.3 / 0.7$ (Jaeglé et al., 2011), which corresponds well to the results from MOCAGE (Table 5). However, the longer mean atmospheric residence time of sea salt particles compared to the AeroCom model average could indicate that the wet deposition and, in particular, below-cloud scavenging, might be underestimated. The below-cloud scavenging is an efficient, episodic process, generally located near to sources, which can strongly influence the residence times of aerosols (Croft et al., 2009), and it is directly proportional to the precipitation intensity. The long lifetime of black carbon aerosols in the model can also indicate that wet deposition - by far the most important sink for black carbon particles (Textor et al., 2006) - could be too weak in MOCAGE. Compared with the data from the Global Precipitation Climatology Project, which is based on ground and satellite observations (Adler et al., 2003), the mean zonal distribution of precipitation in MOCAGE is correctly located, but its intensity is lower for $\approx 25 \%$ (Fig. 11). This affects the simulated quantities that are scavenged and could lead to a longer residence time in MOCAGE than in the AeroCom model average.

The chemical evolution of the sea salt aerosols could have an important impact on the sea salt burden (Lewis and Schwartz, 2004). The tests of the secondary aerosol module performed in MOCAGE show that the dechlorination could be efficient in lowering the sea salt burden (and lifetimes) obtained in this study. Still, the whole impact of the reactions with sea salt aerosols will be possible to evaluate with the secondary inorganic aerosol module validated in the model.

Secondary aerosols can certainly account for the discrepancies between the model and the observations in the zones where anthropogenic aerosols have a major influence, as already discussed. However, the so-called unspecified primary anthropogenic aerosols can also play a role, but the secondary aerosols should have a stronger influence on AOD. The unspecified primary anthropogenic aerosols are not implemented in the configuration of the model used in this study, because they are not present in the emission inventories that we used, but they can be found in some models (e.g. Matthias, 2008).

Updates in the emissions created the largest improvement in our model. But in other studies, uncertainties in the other aerosol parameterizations are found to be bigger than in emissions (Textor et al., 2007). This is backed by the differences in the scavenged aerosols simulated by two different in-cloud scavenging schemes presented in SIM1 and SIM2 that are about $25 \%$. This implies that adding other refine- ments and aiming for more physically realistic parameterizations would likely further improve the model performance. Inclusion of secondary aerosols will be the most crucial addition, it would make the aerosol family more complete and improve the model performance over regions where secondary aerosols and chemical reactions with aerosols play a major role.

\section{Summary and conclusion}

In this paper we introduced the improvements to the aerosol module in the chemical transport model MOCAGE and evaluated the impact on aerosol representation, properties, and global distribution. The ambition was to solve already known model biases and to have more physically realistic aerosol parameterizations. The updates include changes in emissions, wet deposition, and sedimentation. Regarding emissions, we added a SST dependence to the sea salt source function, and adjusted the size distribution (and the wind speed calculation) in the desert dust emission scheme. In the wet deposition scheme we used a new precipitation cloud cover calculation and in-cloud scavenging scheme. We also developed the below-cloud scavenging scheme by revising the calculation of raindrop size and terminal velocity, and by introducing re-evaporation and snowfall scavenging. The sedimentation module update strengthened the performance of the scheme: for example, the model demonstrated better mass conservation. The emission and wet deposition changes produced a stronger impact, while updates in sedimentation produced a less pronounced effect. Emission changes directly influenced known biases of sea salt and African desert dust aerosols, while the impact of wet deposition update is more complex and balanced - depending on the location, it decreased or increased AOD. The effects of the wet deposition updates vary widely, both temporally and spatially, mainly because the wet deposition depends on both the presence of aerosols and the occurrence of precipitation. Examples of the changes in the model field are the increase of AOD in tropical oceans due to introduced re-evaporation in SIM2 compared to SIM1, and the decrease in southern midlatitude oceans due to the changes in the precipitating cloud cover fraction and other updates in the wet deposition scheme.

We evaluated the impacts of these changes and compared them to AOD observations from satellite sensors (MODIS, SEVIRI), the AERONET and the EMEP stations, and the AeroCom model inter-comparison. Since in our model only primary aerosols are present, we focused the analysis on the regions where mainly primary aerosols dominate AOD. Compared to the model simulation with old parameterizations, we significantly improve agreement with the observations and the AeroCom data (Tables 3,4). The sea salt and desert dust emitted quantities correspond better to both estimates from the literature and the model average from the AeroCom project (Table 4). The shift toward smaller particles in 
the desert dust size distribution and the modified geographical distribution of sea salt emissions had a positive impact on aerosol lifetimes. We examined the spatial and temporal variability of AOD and showed that the SST-dependent emissions solved the strong positive bias in sea salt aerosols in mid- to high latitudes that were previously seen in our model (Fig. 4). This lead to a lower AOD over these regions and stronger AOD values over the tropics, which agrees better with observations. In the Saharan desert dust aerosol outflow region, we reduced the bias and improved the correlation and intensity of the stronger events (Table 3). Overall, the updates had a positive effect on the correlation with observations. Quantitatively, as an example, in the comparison with MODIS observations on the global scale, the update of parameterizations improved correlation from 0.06 to 0.32. The comparison with particulate matter $\mathrm{PM}_{2.5} / \mathrm{PM}_{10}$ measurements from the EMEP network showed that in urban zones the model underestimates aerosols, but confirmed the findings obtained from the comparison with AOD measurements that the model updates have positively impacted the model performance.

The obtained results confirmed that large uncertainties in models can come from the use of parameterizations. Significant differences in parameterization formulations lead to big differences in model outputs, as also confirmed in the literature (Textor et al., 2007). Two different in-cloud scavenging schemes used in this study had efficiencies that differed by a factor of 2, and a few changes in different components in our semi-empirical below-cloud scavenging scheme produce very different results in the same scheme.
We found that the introduced updates enhanced the model performance, but some discrepancies with the observations remain: (a) underestimation in the regions where secondary aerosols could have an important impact, (b) some overestimation of sea salt aerosols, and (c) some underestimation of African desert dust aerosols. The future work will address these issues. The inclusion of secondary aerosols in MOCAGE, which is the most important deficiency, is already in progress. The African desert dust emission scheme with a better resolution and satellite-derived soil properties could bring better results over the region. Also, the addition of dust emissions in Australia, North and South America would fill the gap in the global dust emissions in the model.

As mentioned, aerosols have both direct and indirect effects on many atmospheric processes that have relevance to research themes in air quality and climate change. The current development is therefore a necessary stepping stone to being able to conduct studies on these important research topics. The mid-term aim, having added secondary aerosols, would be to carry out studies of air quality studies and to determine the human exposure to aerosols. Another aim would be to calculate the aerosol radiative budget. Another possibility would be to improve the representation of aerosols by using data assimilation or data inversion in the cases where the source term is highly uncertain. 


\section{Appendix A}

This appendix defines the statistical metrics used in this paper. A more detailed review of these statistical terms is given by Huijnen and Eskes (2012), Seigneur et al. (2000) and Boylan and Russell (2006).

The bias is defined as the average difference between paired modelled predicted, $p_{i}$, and measured or reference, $m_{i}$, values:

bias $=\frac{1}{N} \sum_{i=1}^{N}\left(p_{i}-m_{i}\right)$,

where $N$ is the number of pairs $\left(p_{i}, m_{i}\right)$. The bias is an estimation of the general overprediction or underprediction of the model with respect to the measurements.

The modified normalized mean bias, MNMB, is defined as

$\operatorname{MNMB}=\frac{2}{N} \sum_{i=1}^{N} \frac{p_{i}-m_{i}}{p_{i}+m_{i}}$.

It is a measure of the model bias and ranges between -2 and 2 .

The fractional gross error (FGE) is defined as

$\mathrm{FGE}=\frac{2}{N} \sum_{i=1}^{N}\left|\frac{p_{i}-m_{i}}{p_{i}+m_{i}}\right|$.

It is a measure of model error and ranges between 0 and 2.
The MNMB and FGE weight equally overpredictions and underpredictions without overemphasizing outliers and do not consider measurements as the absolute truth. They are useful when prediction and measurement values are strictly positive.

The standard deviation, $\sigma$, indicated the spread from the average value and it is defined as

$\sigma=\sqrt{\frac{1}{N} \sum_{i=1}^{N}\left(p_{i}-\bar{p}\right)^{2}}$,

where $\bar{p}$ is the mean of the predictions.

The correlation coefficient measures the extent to which patterns in the predictions match those in the measurements. It is defined as

$\rho=\frac{\sum_{i=1}^{N}\left(p_{i}-\bar{p}\right)\left(m_{i}-\bar{m}\right)}{\sigma_{\mathrm{p}} \sigma_{\mathrm{m}}}$,

where $\bar{m}$ is the mean of the measurements, and $\sigma_{\mathrm{p}}$ and $\sigma_{\mathrm{m}}$ are the standard deviations of the prediction and the measurements, respectively. 


\section{Code availability}

This paper is based on source code that is presently incorporated inside the MOCAGE model. The MOCAGE source code is the property of Météo-France and CERFACS, and it is based on libraries that belong to some other holders. The MOCAGE model is not open source and routines from MOCAGE cannot be freely distributed. Therefore, we cannot provide the code openly to the $G M D$ website.

Acknowledgements. This work is funded in France by Centre National de Recherches Météorologiques (CNRM-GAME) of Météo-France and Centre National de la Recherche Scientifique (CNRS). The authors would like to thank the AERONET PIs and their staff for establishing and maintaining the sites used in this investigation. We acknowledge the MODIS mission team and scientists for the production of the data used in this study. We also acknowledge NASA/Goddard Space Flight Center's Laboratory for Atmospheres for developing and computing GPCP combined precipitation data and NOAA/OAR/ESRL PSD, Boulder, USA, for providing it, AeroCom and Lamarque et al. (2010) for the emissions of carbonaceous aerosols and the Global Fire Emission Database project for the fire emissions that we used. We thank D. Carrer and his collaborators for developing and providing their SEVIRI-retrieved aerosol data. We also thank the two anonymous reviewers for their constructive comments.

Edited by: T. Butler

\section{References}

Adler, R. F., Huffman, G. J., Chang, A., Ferraro, R., Xie, P.-P., Janowiak, J., Rudolf, B., Schneider, U., Curtis, S., Bolvin, D., Gruber, A., Susskind, J., Arkin, P., and Nelkin, E.: The version-2 Global Precipitation Climatology Project (GPCP) monthly precipitation analysis (1979-present), J. Hydrometeorol., 4, 1147-1167, doi:10.1175/15257541(2003)004<1147:TVGPCP>2.0.CO;2, 2003.

Alfaro, S. C., Gaudichet, A., Gomes, L., and Maillé, M.: Mineral aerosol production by wind erosion: Aerosol particle sizes and binding energies, Geophys. Res. Lett., 25, 991-994, 1998.

Andronache, C.: Estimated variability of below-cloud aerosol removal by rainfall for observed aerosol size distributions, Atmos. Chem. Phys., 3, 131-143, doi:10.5194/acp-3-131-2003, 2003.

Andronache, C.: Diffusion and electric charge contributions to below-cloud wet removal of atmospheric ultra-fine aerosol particles, J. Aerosol Sci., 35, 1467-1482, 2004.

Andronache, C., Grönholm, T., Laakso, L., Phillips, V., and Venäläinen, A.: Scavenging of ultrafine particles by rainfall at a boreal site: observations and model estimations, Atmos. Chem. Phys., 6, 4739-4754, doi:10.5194/acp-6-4739-2006, 2006.

Anguelova, M. D. and Webster, F.: Whitecap coverage from satellite measurements: A first step toward modeling the variability of oceanic whitecaps, J. Geophys. Res.-Oceans, 111, 1978-2012, 2006.

Barré, J., Peuch, V.-H., Attié, J.-L., El Amraoui, L., Lahoz, W. A., Josse, B., Claeyman, M., and Nédélec, P.: Stratosphere- troposphere ozone exchange from high resolution MLS ozone analyses, Atmos. Chem. Phys., 12, 6129-6144, doi:10.5194/acp12-6129-2012, 2012.

Bechtold, P., Bazile, E., Guichard, F., Mascart, P., and Richard, E.: A mass-flux convection scheme for regional and global models, Q. J. Roy. Meteorol. Soc., 127, 869-886, 2001.

Bentamy, A., Queffeulou, P., Quilfen, Y., and Katsaros, K.: Ocean surface wind fields estimated from satellite active and passive microwave instruments, Geoscience and Remote Sensing, IEEE Transactions, 37, 2469-2486, 1999.

Bond, T. C., Streets, D. G., Yarber, K. F., Nelson, S. M., Woo, J.-H., and Klimont, Z.: A technology-based global inventory of black and organic carbon emissions from combustion, J. Geophys. Res.-Atmos., 109, 1984-2012, 2004.

Bond, T. C., Bhardwaj, E., Dong, R., Jogani, R., Jung, S., Roden, C., Streets, D. G., and Trautmann, N. M.: Historical emissions of black and organic carbon aerosol from energy-related combustion, 1850-2000, Global Biogeochem. Cycles, 21, GB2018, doi:10.1029/2006GB002840, 2007.

Bouet, C., Cautenet, G., Bergametti, G., Marticorena, B., Todd, M. C., and Washington, R.: Sensitivity of desert dust emissions to model horizontal grid spacing during the Bodélé Dust Experiment 2005, Atmos. Environ., 50, 377-380, 2012.

Bourassa, M. A., Legler, D. M., O'Brien, J. J., and Smith, S. R.: SeaWinds validation with research vessels, J. Geophys. Res.Oceans, 108, 1978-2012, 2003.

Bousserez, N., Attié, J., Peuch, V. H., Michou, M., Pfister, G., Edwards, D., Emmons, L., Mari, C., Barret, B., Arnold, S., Heckel, A., Richter, A., Schlager, H., Lewis, A., Avery, M., Sachse, G., Browell, E. V., and Hair, J. W.: Evaluation of the MOCAGE chemistry transport model during the ICARTT/ITOP experiment, J. Geophys. Res.-Atmos., 112, 1984-2012, D10S42, doi:10.1029/2006JD007595, 2007.

Boylan, J. W. and Russell, A. G.: PM and light extinction model performance metrics, goals, and criteria for three-dimensional air quality models, Atmos. Environ., 40, 4946-4959, 2006.

Brost, R. A., Feichter, J., and Heimann, M.: Three-dimensional simulation of ${ }^{7} \mathrm{Be}$ in a global climate model, J. Geophys. Res.Atmos., 96, 22423-22445, 1991.

Brown, P. P. and Lawler, D. F.: Sphere drag and settling velocity revisited, J. Environ. Eng., 129, 222-231, doi:10.1061/(ASCE)0733-9372(2003)129:3(222), 2003.

Callot, Y., Marticorena, B., and Bergametti, G.: Geomorphologic approach for modelling the surface features of arid environments in a model of dust emissions: application to the Sahara desert, Geodinamica Acta, 13, 245-270, 2000.

Carrer, D., Roujean, J.-L., Hautecoeur, O., and Elias, T.: Daily estimates of aerosol optical thickness over land surface based on a directional and temporal analysis of SEVIRI MSG visible observations, J. Geophys. Res.-Atmos., 115, D10208, doi:10.1029/2009JD012272, 2010.

Chate, D.: Study of scavenging of submicron-sized aerosol particles by thunderstorm rain events, Atmos. Environ., 39, 6608-6619, 2005.

Chelton, D. B.: The impact of SST specification on ECMWF surface wind stress fields in the eastern tropical Pacific, Journal of climate, 18, 530-550, 2005.

Chelton, D. B. and Freilich, M. H.: Scatterometer-based assessment of 10-m wind analyses from the operational ECMWF and NCEP 
numerical weather prediction models, Mon. Weather Rev., 133, 409-429, 2005.

Croft, B., Lohmann, U., Martin, R. V., Stier, P., Wurzler, S., Feichter, J., Posselt, R., and Ferrachat, S.: Aerosol size-dependent below-cloud scavenging by rain and snow in the ECHAM5HAM, Atmos. Chem. Phys., 9, 4653-4675, doi:10.5194/acp-94653-2009, 2009.

Crumeyrolle, S., Tulet, P., Gomes, L., Garcia-Carreras, L., Flamant, C., Parker, D. J., Matsuki, A., Formenti, P., and Schwarzenboeck, A.: Transport of dust particles from the Bodélé region to the monsoon layer - AMMA case study of the 9-14 June 2006 period, Atmos. Chem. Phys., 11, 479-494, doi:10.5194/acp-11479-2011, 2011.

Davenport, H. M. and Peters, L.: Field studies of atmospheric particulate concentration changes during precipitation, Atmos. Environ., 12, 997-1008, 1978.

Dentener, F., Kinne, S., Bond, T., Boucher, O., Cofala, J., Generoso, S., Ginoux, P., Gong, S., Hoelzemann, J. J., Ito, A., Marelli, L., Penner, J. E., Putaud, J.-P., Textor, C., Schulz, M., van der Werf, G. R., and Wilson, J.: Emissions of primary aerosol and precursor gases in the years 2000 and 1750 prescribed data-sets for AeroCom, Atmos. Chem. Phys., 6, 4321-4344, doi:10.5194/acp-64321-2006, 2006.

Dufour, A., Amodei, M., Ancellet, G., and Peuch, V.-H.: Observed and modelled "chemical weather" during ESCOMPTE, Atmos. Res., 74, 161-189, doi:10.1016/j.atmosres.2004.04.013, 2005.

El Amraoui, L., Attié, J.-L., Semane, N., Claeyman, M., Peuch, V.H., Warner, J., Ricaud, P., Cammas, J.-P., Piacentini, A., Josse, B., Cariolle, D., Massart, S., and Bencherif, H.: Midlatitude stratosphere - troposphere exchange as diagnosed by MLS $\mathrm{O}_{3}$ and MOPITT CO assimilated fields, Atmos. Chem. Phys., 10, 2175-2194, doi:10.5194/acp-10-2175-2010, 2010.

Fan, T. and Toon, O. B.: Modeling sea-salt aerosol in a coupled climate and sectional microphysical model: mass, optical depth and number concentration, Atmos. Chem. Phys., 11, 4587-4610, doi:10.5194/acp-11-4587-2011, 2011.

Gerber, H. E.: Relative-humidity parameterization of the Navy Aerosol Model (NAM), Tech. Rep. NRL Report 8956, Naval Research Laboratory, 1985.

Giorgi, F. and Chameides, W. L.: Rainout lifetimes of highly soluble aerosols and gases as inferred from simulations with a general circulation model, J. Geophys. Res.-Atmos., 91, 14367-14376, 1986.

Gong, S.: A parameterization of sea-salt aerosol source function for sub-and super-micron particles, Global Biogeochem. Cycles, 17, 1097, doi:10.1029/2003GB002079, 2003.

Gong, S., Barrie, L., and Blanchet, J.-P.: Modeling sea-salt aerosols in the atmosphere: 1. Model development, J. Geophys. Res.Atmos., 102, 3805-3818, 1997.

Holben, B. N., Eck, T. F., Slutsker, I., Tanre, D., Buis, J. P., Setzer, A., Vermote, E., Reagan, J. A., Kaufman, Y. J., Nakajima, T., Lavenu, F., Jankowiak, I., and Smirnov, A.: AERONET - A federated instrument network and data archive for aerosol characterization, Rem. Sens. Environ., 66, 1-16, doi:10.1016/S00344257(98)00031-5, 1998.

Huijnen, V. and Eskes, H.: Skill scores and evaluation methodology for the MACC II project, Tech. rep., available at www.gmes-atmosphere.eu/documents/maccii/deliverables/val/
MACCII_VAL_DEL_D_85.2_ScoringReport01_20120222.pdf (last access: 15 October 2014), 2012.

Ichoku, C., Remer, L. A., and Eck, T. F.: Quantitative evaluation and intercomparison of morning and afternoon Moderate Resolution Imaging Spectroradiometer (MODIS) aerosol measurements from Terra and Aqua, J. Geophys. Res.-Atmos., 110, D10S99, doi:10.1029/2004JD004987, 2005.

IPCC: Climate change 2007: The physical science basis: Working Group I Contribution to the Fourth Assessment Report of the Intergovernmental Panel on Climate Change, Cambridge University Press, Cambridge and New York, 2007.

IPCC: Climate change 2013: The physical science basis: Working Group I Contribution to the Fifth Assessment Report of the Intergovernmental Panel on Climate Change, Cambridge University Press, Cambridge and New York, 2013.

Jacob, D., Liu, H., Mari, C., and Yantosca, R.: Harvard wet deposition scheme for GMI, Tech. rep., Harvard University Atmospheric Chemistry Modeling Group, available at gmi.gsfc.nasa. gov/models/jacob_wetdep.pdf (last access: 1 December 2013), 2000 .

Jaeglé, L., Quinn, P. K., Bates, T. S., Alexander, B., and Lin, J.-T.: Global distribution of sea salt aerosols: new constraints from in situ and remote sensing observations, Atmos. Chem. Phys., 11, 3137-3157, doi:10.5194/acp-11-3137-2011, 2011.

Josse, B., Simon, P., and Peuch, V.-H.: Radon global simulations with the multiscale chemistry and transport model MOCAGE, Tellus B, 56, 339-356, 2004.

Junker, C. and Liousse, C.: A global emission inventory of carbonaceous aerosol from historic records of fossil fuel and biofuel consumption for the period 1860-1997, Atmos. Chem. Phys., 8, 1195-1207, doi:10.5194/acp-8-1195-2008, 2008.

Kahn, R. A., Gaitley, B. J., Martonchik, J. V., Diner, D. J., Crean, K. A., and Holben, B.: Multiangle Imaging Spectroradiometer (MISR) global aerosol optical depth validation based on 2 years of coincident Aerosol Robotic Network (AERONET) observations, J. Geophys. Res.-Atmos., 110, D10S04, doi:10.1029/2004JD004706, 2005.

Kasper-Giebl, A., Koch, A., Hitzenberger, R., and Puxbaum, H.: Scavenging efficiency of "aerosol carbon" and sulfate in supercooled clouds at Mt. Sonnblick (3106 m asl, Austria), J. Atmos. Chem., 35, 33-46, 2000.

Kessler, E.: On the distribution and continuity of water substance in atmospheric circulation, Met. Monograph, 10, 84, doi:10.1016/0169-8095(94)00090-Z, 1969.

Köpke, P., Hess, M., Schult, I., and Shettle, E.: Global aerosol data set, Tech. Rep. MPI Report No 243, Max-Planck-Institut für Meteorologie, Hamburg, Germany, 1997.

Koren, I., Remer, L. A., Kaufman, Y. J., Rudich, Y., and Martins, J. V.: On the twilight zone between clouds and aerosols, Geophys. Res. Lett., 34, L08805, doi:10.1029/2007g1029253, 2007.

Laakso, L., Grönholm, T., Rannik, Ü., Kosmale, M., Fiedler, V., Vehkamäki, H., and Kulmala, M.: Ultrafine particle scavenging coefficients calculated from 6 years field measurements, Atmos. Environ., 37, 3605-3613, 2003.

Lamarque, J.-F., Bond, T. C., Eyring, V., Granier, C., Heil, A., Klimont, Z., Lee, D., Liousse, C., Mieville, A., Owen, B., Schultz, M. G., Shindell, D., Smith, S. J., Stehfest, E., Van Aardenne, J., Cooper, O. R., Kainuma, M., Mahowald, N., McConnell, J. R., Naik, V., Riahi, K., and van Vuuren, D. P.: His- 
torical (1850-2000) gridded anthropogenic and biomass burning emissions of reactive gases and aerosols: methodology and application, Atmos. Chem. Phys., 10, 7017-7039, doi:10.5194/acp10-7017-2010, 2010.

Lamarque, J.-F., Shindell, D. T., Josse, B., Young, P. J., Cionni, I., Eyring, V., Bergmann, D., Cameron-Smith, P., Collins, W. J., Doherty, R., Dalsoren, S., Faluvegi, G., Folberth, G., Ghan, S. J., Horowitz, L. W., Lee, Y. H., MacKenzie, I. A., Nagashima, T., Naik, V., Plummer, D., Righi, M., Rumbold, S. T., Schulz, M., Skeie, R. B., Stevenson, D. S., Strode, S., Sudo, K., Szopa, S., Voulgarakis, A., and Zeng, G.: The Atmospheric Chemistry and Climate Model Intercomparison Project (ACCMIP): overview and description of models, simulations and climate diagnostics, Geosci. Model Dev., 6, 179-206, doi:10.5194/gmd-6-179-2013, 2013.

Langner, J. and Rodhe, H.: A global three-dimensional model of the tropospheric sulfur cycle, J. Atmos. Chem., 13, 225-263, doi:10.1007/BF00058134, 1991.

Laurent, B., Marticorena, B., Bergametti, G., and Mei, F.: Modeling mineral dust emissions from Chinese and Mongolian deserts, Glob. Planet. Change, 52, 121-141, 2006.

Laurent, B., Heinold, B., Tegen, I., Bouet, C., and Cautenet, G.: Surface wind accuracy for modeling mineral dust emissions: Comparing two regional models in a Bodélé case study, Geophys. Res. Lett., 35, L09804, doi:10.1029/2008GL033654, 2008a.

Laurent, B., Marticorena, B., Bergametti, G., Léon, J., and Mahowald, N.: Modeling mineral dust emissions from the Sahara desert using new surface properties and soil database, J. Geophys. Res.-Atmos., 113, D14218, doi:10.1029/2007JD009484, 2008b.

Lee, L. A., Carslaw, K. S., Pringle, K. J., Mann, G. W., and Spracklen, D. V.: Emulation of a complex global aerosol model to quantify sensitivity to uncertain parameters, Atmos. Chem. Phys., 11, 12253-12273, doi:10.5194/acp-11-12253-2011, 2011.

Lewis, R. and Schwartz, E.: Sea salt aerosol production: mechanisms, methods, measurements and models - a critical review, vol. 152, American Geophysical Union, 2004.

Liu, H., Jacob, D. J., Bey, I., and Yantosca, R. M.: Constraints from ${ }^{210} \mathrm{~Pb}$ and ${ }^{7} \mathrm{Be}$ on wet deposition and transport in a global threedimensional chemical tracer model driven by assimilated meteorological fields, J. Geophys. Res.-Atmos., 106, 12109-12128, 2001.

Louis, J.-F.: A parametric model of vertical eddy fluxes in the atmosphere, Bound.-Layer Meteorol., 17, 187-202, 1979.

Mahowald, N., Luo, C., del Corral, J., and Zender, C. S.: Interannual variability in atmospheric mineral aerosols from a 22-year model simulation and observational data, J. Geophys. Res.-Atmos., 108, 4352, doi:10.1029/2002JD002821, 2003.

Marshall, J. S. and Palmer, W. M. K.: The distribution of raindrops with size, J. Meteorol., 5, 165-166, 1948.

Martet, M., Peuch, V.-H., Laurent, B., Marticorena, B., and Bergametti, G.: Evaluation of long-range transport and deposition of desert dust with the CTM MOCAGE, Tellus B, 61, 449-463, doi:10.3402/tellusb.v61i2.16843, 2009.

Marticorena, B., Bergametti, G., Aumont, B., Callot, Y., N'doumé, C., and Legrand, M.: Modeling the atmospheric dust cycle: 2. Simulation of Saharan dust sources, J. Geophys. Res.-Atmos., 102, 4387-4404, doi:10.1029/96JD02964, 1997.
Matthias, V.: The aerosol distribution in Europe derived with the Community Multiscale Air Quality (CMAQ) model: comparison to near surface in situ and sunphotometer measurements, Atmos. Chem. Phys., 8, 5077-5097, doi:10.5194/acp-8-5077-2008, 2008.

Mei, F., Zhang, X., Lu, H., Shen, Z., and Wang, Y.: Characterization of MASDs of surface soils in north China and its influence on estimating dust emission, Chinese Science Bulletin, 49, 21692176, 2004.

Monahan, E. C., Spiel, D. E., and Davidson, K. L.: A model of marine aerosol generation via whitecaps and wave disruption, in: Oceanic whitecaps and their role in air-sea exchange processes, edited by: Monahan, E. C. and Niocaill, G. M., pp. 167-174, D. Reidel Publishing, Dordrecht, Holland, 1986.

Mu, M., Randerson, J. T., van der Werf, G. R., Giglio, L., Kasibhatla, P., Morton, D., Collatz, G. J., DeFries, R. S., Hyer, E. J., Prins, E. M., Griffith, D. W. T., Wunch, D., Toon, G. C., Sherlock, V., and Wennberg, P. O.: Daily and 3-hourly variability in global fire emissions and consequences for atmospheric model predictions of carbon monoxide, J. Geophys. Res.-Atmos., 116, D24303, doi:10.1029/2011JD016245, 2011.

Nho-Kim, E.-Y., Michou, M., and Peuch, V.-H.: Parameterization of size-dependent particle dry deposition velocities for global modeling, Atmos. Environ., 38, 1933-1942, 2004.

Prospero, J. M., Landing, W. M., and Schulz, M.: African dust deposition to Florida: Temporal and spatial variability and comparisons to models, J. Geophys. Res.-Atmos., 115, D13304, doi:10.1029/2009JD012773, 2010.

Pruppacher, H. R. and Klett, J. D.: Microphysics of clouds and precipitation, D. Reidel, Hingham, MA, 1978.

Pruppacher, H. R., Klett, J. D., and Wang, P. K.: Microphysics of clouds and precipitation, Kluwer Academic Publishers, Dordrecht, 1997.

Rasch, P. J., Feichter, J., Law, K., Mahowald, N., Penner, J., Benkovitz, C., Genthon, C., Giannakopoulos, C., Kasibhatla, P., Koch, D., Levy, H., Maki, T., Prather, M., Roberts, D. L., Roelofs, G.-J., Stevenson, D., Stockwell, Z., Taguchi, S., Kritz, M., Chipperfield, M., Baldocchi, D., Mcmurry, P., Barrie, L., Balkanski, Y., Chatfield, R., Kjellstrom, E., Lawrence, M., Lee, H. N., Lelieveld, J., Noone, K. J., Seinfeld, J., Stenchikov, G., Schwartz, S., Walcek, C., and Williamson, D.: A comparison of scavenging and deposition processes in global models: results from the WCRP Cambridge Workshop of 1995, Tellus B, 52, 1025-1056, 2000.

Remer, L. A., Kaufman, Y., Tanré, D., Mattoo, S., Chu, D., Martins, J. V., Li, R.-R., Ichoku, C., Levy, R., Kleidman, R., and Holben, B.: The MODIS aerosol algorithm, products, and validation, J. Atmos. Sci., 62, 947-973, 2005.

Remer, L. A., Kleidman, R. G., Levy, R. C., Kaufman, Y. J., Tanré, D., Mattoo, S., Martins, J. V., Ichoku, C., Koren, I., Yu, H., and Holben, B.: Global aerosol climatology from the MODIS satellite sensors, J. Geophys. Res.-Atmos., 113, D14S07, doi:10.1029/2007JD009661, 2008.

Reynolds, R. W., Rayner, N. A., Smith, T. M., Stokes, D. C., and Wang, W.: An improved in situ and satellite SST analysis for climate, J. Climate, 15, 1609-1625, 2002.

Ricaud, P., Attié, J.-L., Teyssèdre, H., El Amraoui, L., Peuch, V.H., Matricardi, M., and Schluessel, P.: Equatorial total column of nitrous oxide as measured by IASI on MetOp-A: implica- 
tions for transport processes, Atmos. Chem. Phys., 9, 39473956, doi:10.5194/acp-9-3947-2009, 2009.

Schuster, G. L., Vaughan, M., MacDonnell, D., Su, W., Winker, D., Dubovik, O., Lapyonok, T., and Trepte, C.: Comparison of CALIPSO aerosol optical depth retrievals to A ERONET measurements, and a climatology for the lidar ratio of dust, Atmos. Chem. Phys., 12, 7431-7452, doi:10.5194/acp-12-7431-2012, 2012.

Seigneur, C., Pun, B., Pai, P., Louis, J.-F., Solomon, P., Emery, C., Morris, R., Zahniser, M., Worsnop, D., Koutrakis, P., White, W., and Tombach, I.: Guidance for the performance evaluation of three-dimensional air quality modeling systems for particulate matter and visibility, J. Air Waste Manag. Assoc., 50, 588-599, 2000.

Seinfeld, J. H. and Pandis, S. N.: Atmospheric chemistry and physics: from air pollution to climate change, John Wiley \& Sons, New York, USA, 1998.

Slinn, S. and Slinn, W.: Predictions for particle deposition on natural waters, Atmos. Environ., 14, 1013-1016, doi:10.1016/00046981(80)90032-3, 1980.

Slinn, W.: Some approximations for the wet and dry removal of particles and gases from the atmosphere, Water, Air, Soil Pollut., 7, 513-543, 1977.

Slinn, W.: Estimates for the long-range transport of air pollution, Water, Air, and Soil Pollution, pp. 45-64, doi:10.1007/978-94009-7966-6_4, 1982a.

Slinn, W.: Predictions for particle deposition to vegetative canopies, Atmos. Environ., 16, 1785-1794, doi:10.1016/00046981(82)90271-2, 1982b.

Slinn, W. and Hales, J.: A reevaluation of the role of thermophoresis as a mechanism of in-and below-cloud scavenging, J. Atmos. Sci., 28, 1465-1471, 1971.

Spada, M., Jorba, O., Pérez García-Pando, C., Janjic, Z., and Baldasano, J. M.: Modeling and evaluation of the global sea-salt aerosol distribution: sensitivity to size-resolved and sea-surface temperature dependent emission schemes, Atmos. Chem. Phys., 13, 11735-11755, doi:10.5194/acp-13-11735-2013, 2013.

Sportisse, B.: A review of parameterizations for modelling dry deposition and scavenging of radionuclides, Atmos. Environ., 41, 2683-2698, 2007.

Su, W., Loeb, N. G., Schuster, G. L., Chin, M., and Rose, F. G.: Global all-sky shortwave direct radiative forcing of anthropogenic aerosols from combined satellite observations and GOCART simulations, J. Geophys. Res.-Atmos., 118, 655-669, doi:10.1029/2012JD018294, 2013.

Tegen, I.: Modeling the mineral dust aerosol cycle in the climate system, Quat. Sci. Rev., 22, 1821-1834, 2003.

Textor, C., Schulz, M., Guibert, S., Kinne, S., Balkanski, Y., Bauer, S., Berntsen, T., Berglen, T., Boucher, O., Chin, M., Dentener, F., Diehl, T., Easter, R., Feichter, H., Fillmore, D., Ghan, S., Ginoux, P., Gong, S., Grini, A., Hendricks, J., Horowitz, L., Huang, P., Isaksen, I., Iversen, I., Kloster, S., Koch, D., Kirkevåg, A., Kristjansson, J. E., Krol, M., Lauer, A., Lamarque, J. F., Liu, X., Montanaro, V., Myhre, G., Penner, J., Pitari, G., Reddy, S., Seland, $\varnothing$., Stier, P., Takemura, T., and Tie, X.: Analysis and quantification of the diversities of aerosol life cycles within AeroCom, Atmos. Chem. Phys., 6, 1777-1813, doi:10.5194/acp-6-1777-2006, 2006.
Textor, C., Schulz, M., Guibert, S., Kinne, S., Balkanski, Y., Bauer, S., Berntsen, T., Berglen, T., Boucher, O., Chin, M., Dentener, F., Diehl, T., Feichter, J., Fillmore, D., Ginoux, P., Gong, S., Grini, A., Hendricks, J., Horowitz, L., Huang, P., Isaksen, I. S. A., Iversen, T., Kloster, S., Koch, D., Kirkevåg, A., Kristjansson, J. E., Krol, M., Lauer, A., Lamarque, J. F., Liu, X., Montanaro, V., Myhre, G., Penner, J. E., Pitari, G., Reddy, M. S., Seland, Ø., Stier, P., Takemura, T., and Tie, X.: The effect of harmonized emissions on aerosol properties in global models an AeroCom experiment, Atmos. Chem. Phys., 7, 4489-4501, doi:10.5194/acp-7-4489-2007, 2007.

Teyssèdre, H., Michou, M., Clark, H. L., Josse, B., Karcher, F., Olivié, D., Peuch, V.-H., Saint-Martin, D., Cariolle, D., Attié, J.-L., Nédélec, P., Ricaud, P., Thouret, V., van der A, R. J., VolzThomas, A., and Chéroux, F.: A new tropospheric and stratospheric Chemistry and Transport Model MOCAGE-Climat for multi-year studies: evaluation of the present-day climatology and sensitivity to surface processes, Atmos. Chem. Phys., 7, 58155860, doi:10.5194/acp-7-5815-2007, 2007.

Todd, C.: A system for computing ice phase hydrometeor development, Tech. Rep. ARG Report 64, Paper 121, Atmopsheric Research Group, Altadena, 1964.

Tørseth, K., Aas, W., Breivik, K., Fjæraa, A. M., Fiebig, M., Hjellbrekke, A. G., Lund Myhre, C., Solberg, S., and Yttri, K. E.: Introduction to the European Monitoring and Evaluation Programme (EMEP) and observed atmospheric composition change during 1972-2009, Atmos. Chem. Phys., 12, 5447-5481, doi:10.5194/acp-12-5447-2012, 2012.

van der Werf, G. R., Randerson, J. T., Giglio, L., Collatz, G. J., Mu, M., Kasibhatla, P. S., Morton, D. C., DeFries, R. S., Jin, Y., and van Leeuwen, T. T.: Global fire emissions and the contribution of deforestation, savanna, forest, agricultural, and peat fires (19972009), Atmos. Chem. Phys., 10, 11707-11735, doi:10.5194/acp10-11707-2010, 2010.

Vignati, E., Karl, M., Krol, M., Wilson, J., Stier, P., and Cavalli, F.: Sources of uncertainties in modelling black carbon at the global scale, Atmos. Chem. Phys., 10, 2595-2611, doi:10.5194/acp-102595-2010, 2010.

Wang, X., Zhang, L., and Moran, M. D.: Uncertainty assessment of current size-resolved parameterizations for below-cloud particle scavenging by rain, Atmos. Chem. Phys., 10, 5685-5705, doi:10.5194/acp-10-5685-2010, 2010.

White, F. M.: Viscous fluid flow, McGraw-Hill New York, 1991.

Williams, J. E., Scheele, M. P., van Velthoven, P. F. J., Cammas, J.-P., Thouret, V., Galy-Lacaux, C., and Volz-Thomas, A.: The influence of biogenic emissions from Africa on tropical tropospheric ozone during 2006: a global modeling study, Atmos. Chem. Phys., 9, 5729-5749, doi:10.5194/acp-9-5729-2009, 2009.

Williamson, D. L. and Rasch, P. J.: Two-dimensional semiLagrangian transport with shape-preserving interpolation, Mon. Weather Rev., 117, 102-129, 1989.

Wiscombe, W. J.: Improved Mie scattering algorithms, Appl. Optics, 19, 1505-1509, 1980.

Xu, K.-M. and Randall, D. A.: A semiempirical cloudiness parameterization for use in climate models, J. Atmos. Sci., 53, 3084 3102, 1996.

Zhang, J., Reid, J. S., and Holben, B. N.: An analysis of potential cloud artifacts in MODIS over ocean aerosol op- 
tical thickness products, Geophys. Res. Let., 32, L15803, doi:10.1029/2005GL023254, 2005.

Zhang, K., O’Donnell, D., Kazil, J., Stier, P., Kinne, S., Lohmann, U., Ferrachat, S., Croft, B., Quaas, J., Wan, H., Rast, S., and Feichter, J.: The global aerosol-climate model ECHAM-HAM, version 2: sensitivity to improvements in process representations, Atmos. Chem. Phys., 12, 8911-8949, doi:10.5194/acp-12-89112012, 2012.
Zhang, L., Wang, X., Moran, M. D., and Feng, J.: Review and uncertainty assessment of size-resolved scavenging coefficient formulations for below-cloud snow scavenging of atmospheric aerosols, Atmos. Chem. Phys., 13, 10005-10025, doi:10.5194/acp-13-10005-2013, 2013.

Zhao, T., Gong, S. L., Zhang, X., Abdel-Mawgoud, A., and Shao, Y.: An assessment of dust emission schemes in modeling east Asian dust storms, J. Geophys. Res.-Atmos., 111, D05S90, doi:10.1029/2004JD005746, 2006. 